Florida International University FIU Digital Commons

6-20-2016

\title{
Income Distribution, International Trade and Foreign Direct Investment with Heterogeneous Firms
}

Feifei Wang

fwang011@fiu.edu

DOI: 10.25148 /etd.FIDC000691

Follow this and additional works at: https://digitalcommons.fiu.edu/etd

Part of the Economics Commons

\section{Recommended Citation}

Wang, Feifei, "Income Distribution, International Trade and Foreign Direct Investment with Heterogeneous Firms" (2016). FIU Electronic Theses and Dissertations. 2545.

https://digitalcommons.fiu.edu/etd/2545 


\section{FLORIDA INTERNATIONAL UNIVERSITY \\ Miami, Florida}

\section{INCOME DISTRIBUTION, INTERNATIONAL TRADE AND FOREIGN DIRECT INVESTMENT WITH HETEROGENEOUS FIRMS}

A dissertation submitted in partial fulfillment of the requirements for the degree of DOCTOR OF PHILOSOPHY in ECONOMICS

by

Feifei Wang 
To: Dean John F. Stack, Jr.

Steven J. Green School of International and Public Affairs

This dissertation, written by Feifei Wang, and entitled Income Distribution, International Trade and Foreign Direct Investment with Heterogeneous Firms, having been approved in respect to style and intellectual content, is referred to you for judgment.

We have read this dissertation and recommend that it be approved.

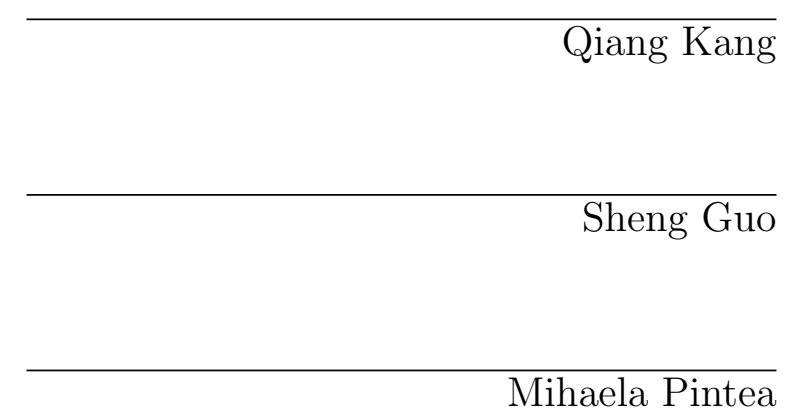

Mihaela Pintea

Kaz Miyagiwa, Major Professor

Date of Defense: June 20, 2016

The dissertation of Feifei Wang is approved.

Dean John F. Stack, Jr. Steven J. Green School of International and Public Affairs

Dean Andrés G. Gil

Vice President for Research and Economic Development and Dean of the University Graduate School

Florida International University, 2016 


\section{ACKNOWLEDGMENTS}

I would never have been able to finish my dissertation without the guidance of my committee members, help from friends, and support from my family. I would like to express my sincere gratitude to my major advisor Prof. Kaz Miyagiwa for the guidance, caring, immense knowledge, and providing me with an ideal atmosphere for doing research. Besides my advisor, I would like to thank the rest of my dissertation committee members: Prof. Qiang Kang, Prof. Sheng Guo, and Prof. Mihaela Pintea, for their comments and encouragement. Last but not the least, I would like to thank my parents for supporting me spiritually throughout writing this dissertation with their best wishes. 


\section{ABSTRACT OF THE DISSERTATION \\ INCOME DISTRIBUTION, INTERNATIONAL TRADE AND FOREIGN \\ DIRECT INVESTMENT WITH HETEROGENEOUS FIRMS \\ by}

Feifei Wang

Florida International University, 2016

Miami, Florida

Professor Kaz Miyagiwa, Major Professor

This dissertation investigates the factors that firms take into consideration when they decide in which manner to expand internationally (i.e. foreign direct investment and international trade). Another component of the investigation focuses on what types of firms benefit the most and what are the associated benefits with expanding internationally.

I investigate self-selection and learning-by-exporting hypothesis by applying matched sampling techniques and non-structural econometric models. Using a Chinese firmlevel dataset, I find that firms that start exporting are more productive than nonexporting ones. Additionally, in most industries exporters become more productive in time.

I then investigate how income inequality leads firms to make different choices on how they expand internationally. I develop a simple theoretical model by carefully choosing a mean-preserving income distribution. I find that changing the meanpreserving parameter of the income distribution affects market demand for firms' products and firms' choosing of strategies for international expansion. Some, but not all firms gain market shares due to larger market size caused by the more concentrated income distribution around the mean. Using Gini coefficient as the proxy for income distribution, I demonstrate empirically that some firms gain market 
shares and benefit from more consumers becoming part of the middle class due to the corresponding change in income distribution.

I also study the aggregate implication of opening the economy in a two-country Dynamic Stochastic Equilibrium in which firms have heterogeneous productivity in the spirit of Melitz (2003). I show that benefits incurred by international engagement are not equally distributed among firms. I separate firms into four categories based on their productivity levels. The highest productivity firms gain the most by breaking into a new market as multinationals. The second highest productivity firms become exporters and obtain the second largest market share. The third highest productivity firms only serve the domestic market, while the lowest productivity firms exit the market. 


\section{TABLE OF CONTENTS}

CHAPTER

PAGE

1. INTRODUCTION . . . . . . . . . . . . . . . . . 1

1.1 Data and preliminary analysis . . . . . . . . . . . . 4

1.1 .1 Data description . . . . . . . . . . . . . . . . 4

1.1 .2 Preliminary analysis . . . . . . . . . . . . . . . . . . 8

1.2 Productivity estimation . . . . . . . . . . . . . . . . . . . 11

1.3 Econometric models . . . . . . . . . . . . . . . . . . . . 16

1.3.1 Test the self-selection hypothesis . . . . . . . . . . . . . . 16

1.3.2 Propensity score and matching . . . . . . . . . . . . . . . . . 18

1.3.3 The average effect of treatment on the treated . . . . . . . . . . . . 21

1.3.4 Estimated results . . . . . . . . . . . . . . . . . . . . . . 22

1.4 Conclusion . . . . . . . . . . . . . . . . . . . . . . . . . 25

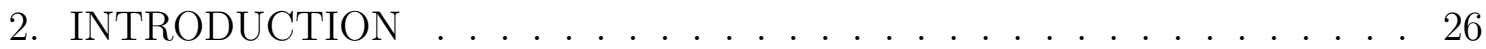

2.1 Model . . . . . . . . . . . . . . . . . . . . . . . . 30

2.1.1 Modeling the income distribution . . . . . . . . . . . . . . . 30

2.2 International expansion . . . . . . . . . . . . . . . . . . . . 34

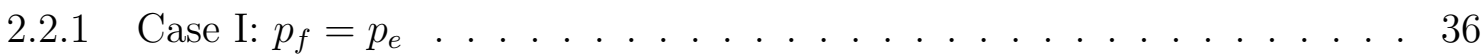

2.2 .2 Case II: $p_{f} \neq p_{e}$ and $p$ in the same interval . . . . . . . . . 38

2.2 .3 Case III: $p_{f} \neq p_{e}$ and $p$ in different intervals . . . . . . . . . . . 40

2.3 Empirical Model . . . . . . . . . . . . . . . . . . . . . . . 42

2.4 Data description . . . . . . . . . . . . . . . . . . . . . . . . 42

2.4.1 Model specification . . . . . . . . . . . . . . . . . . . . . . 43

2.4 .2 Results . . . . . . . . . . . . . . . . . . . . . . . . 47

2.5 Conclusion . . . . . . . . . . . . . . . . . . . . 51

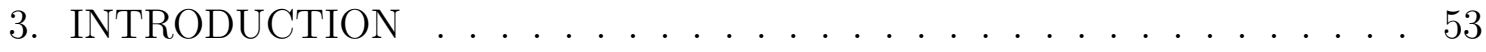

3.1 Model background . . . . . . . . . . . . . . . . . . . . . . 54

3.2 Model setup . . . . . . . . . . . . . . . . . . . . . . . . . 55

3.2 .1 Demand . . . . . . . . . . . . . . . . . . . . . 56

3.3 Production . . . . . . . . . . . . . . . . . . . . . . . 59

3.4 Firm Entry and Exit in Autarky _. . . . . . . . . . . . . . 60

3.4 .1 Equilibrium in autarky . . . . . . . . . . . . . . . . . 63

3.5 International Expansion . . . . . . . . . . . . . . . . . 63

3.6 Labor Market in the open economy . . . . . . . . . . . . . . . . 66

3.7 Aggregation and equilibrium in the open economy . . . . . . . . . 68

3.8 National account and Terms of Trade . . . . . . . . . . . . . . . . 71

3.9 Conclusion . . . . . . . . . . . . . . . . . . . . . . . . . 72

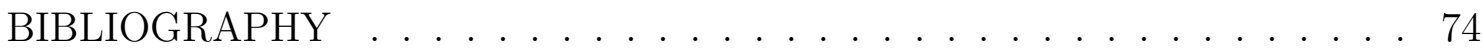




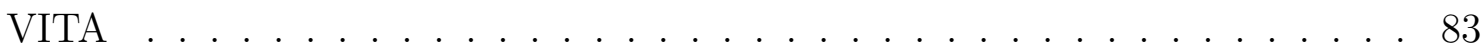




\section{LIST OF TABLES}

TABLE

PAGE

1.1 Summary statistics for exporters and non-exporters . . . . . . . . . 7

1.2 Firm characteristics differences between non-exporters and exporters . . 11

1.3 Firms' decision to export . . . . . . . . . . . . . . . . 17

1.4 Estimated learning-by-exporting effects for selected industries . . . . . . 24

2.1 Summary of all cases . . . . . . . . . . . . . . . . . 41

2.2 OLS estimates . . . . . . . . . . . . . . . . . . . . . . . . 48

2.3 OLS and LSFE estimates . . . . . . . . . . . . . . . . . 50 


\section{LIST OF FIGURES}

FIGURE

PAGE

1.1 Average cost ratio between exporters and non-exporters . . . . . . . 6

1.2 Productivity trajectories of grouped exporters and non-exporters . . . . 9

1.3 Firm characteristics differences between non-exporters and exporters . . 10

1.4 Overall Productivity Trajectory for non-exporters and exporters . . . . . 12

2.1 Double crossing density functions, single crossing CDFs and $F_{\alpha}(I, \alpha)$

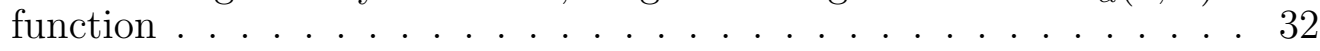

2.2 Scatterplots: i) export-FDI ratio and Gini coefficients (up), ii) FDI affiliate sales and Gini coefficients (down) . . . . . . . . . . . 44 


\section{CHAPTER 1 \\ INTRODUCTION}

China has become the second largest economy in the world and is known as one of the export-oriented countries thanks to its open-door policy that was enacted in the late eighties of last century. Manufactures exports play a very important role in the overall merchandise exports of China. On average China's manufactures exports accounts for $90 \%$ of China's total merchandise exports. ${ }^{1}$ China's unique role in the world export market provides a rich background to analyze the relationship between export behavior and firm performance. The supporting anecdotal evidence is abundant and suggest large benefits gained by firms who engage in export activities. ${ }^{2}$ However, doubts about whether the export economy realizes higher productivity in manufacturing sector still linger.

Bernard and Jensen (1999) propose two hypothese to explain the positive relationship between exporting activities and better performed firms. One hypothesis is the self-selection hypothesis, which states that more productive firms self-select themselves into the export market because they are usually larger and can overcome the extra costs involved in exporting products. The premise for self-selection hypothesis is that competition is tougher in the international market than the domestic one because exporting firms are in a larger market and face more competitors. High productivity is accrued prior to entering the exporting market. ${ }^{3}$ The other hypoth-

\footnotetext{
${ }^{1}$ The data source is acquired from the Worldbank database.

${ }^{2}$ Rhee, Pursell, and Ross-Larson (1984) documented the guiding role of foreign buyers in the early development of Korean manufacturing. World Bank (1998) writes in a report that "... export is one of the most important ways for contunries to obtain knowledge from abroad. ", Blalock and Gertler (2004) interviewed several Indonesian exporting factory managers and found similar evidence.

${ }^{3}$ Bernard and Wagner, 1997; Bernard and Jensen, 1999 and 2004; Aw and Huang, 1995; Clerides, Lach, and Tybout, 1998; Aw, Chung, and Roberts 2000; Delgado et al.,
} 
esis is the learning-by-exporting hypothesis. Firms participating in international markets are exposed to more intense competition hence are more likely to grow faster than their domestic counterparts through the knowledge transfer from foreign buyers. Broadly speaking, learning-by-exporting includes knowledge, technology transfer, and operational efficiencies that a firm may acquire through participating in the international market by exporting. ${ }^{4}$ What is interesting is that empirical evidence documenting technology acquisition through exporting is scarce. Many research works seeking to investigate the causal relationship between exporting and firm productivity reject the learning-by-exporting hypothesis. ${ }^{5}$ However, Van Biesebrock (2005) and Blalock and Gertler (2004) find results that support the learningby-exporting hypothesis by examining cases of very poor countries: sub-Saharan African countries and Indonesia, respectively. And Aw, Chung, and Roberts (2000) for Korea and Gimma et al. (2003) for UK both document significant productivity increases after entering the export.

Moreover, Martins and Yang (2009) use a meta-analysis approach to examine 30 papers that study the causal relationship between exporting and firm productivity. ${ }^{6}$ They find that the impact of exporting on productivity is higher for developing countries than for developed countries and that such impact is higher in the first year of exporting than at later years. Findings of learning-by-exporting in the less developed countries or developing countries may shed some light on a deduction that 2002; Castellani, 2002; Arnold and Hussinger, 20004; Alvarez and Lopez, 2004; and Lopez 2009 .

${ }^{4}$ Blalock and Gertler, 2004.

${ }^{5}$ Clerides, Lach, and Tybout 1998, Bernard and Jensen 1999, Kraay 1999, Delgado, Farinas, and Ruano 2002, Wagner 2004, De Loecker 2007; Aw, Roberts and Winston 2007; and Lileeva and Trefler 2010.

${ }^{6}$ Card and Krueger 1995; Ashenfelter et al. 1999; Pereira and Martins 2004. 
firms in poor countries have more to gain from exposure to international market than firms in developed countries. Exporting firms may receive technical assistance from international buyers and such knowledge eventually diffuses to other sellers. Additionally, firms participating in international markets are exposed to more intense competition hence may grow faster than their domestic counterparts through the knowledge transfer from foreign buyers.

These aforementioned empirical results provide mixed evidences about the impact of exporting on firms' performance. Nevertheless, those findings underscore a potential for economic development through international trade, and raise an important question about the causal relationship between exporting and productivity. ${ }^{7}$

This paper examines the self-selection hypothesis and investigates the possible causal relationship between exporting and firm performance using a rich Chinese firm-level dataset covering the entire manufacturing sector of China for the period from 1998 to $2007 .^{8}$ To my knowledge, this study is the first empirical attempt to directly track the before-and-after exporting performance of Chinese manufacturing firms.

Using the constructed Ollay-Pakes total factor productivity as the performance measure, I deploy a linear probability model controlling for fixed effects to examine the self-selection hypothesis. ${ }^{9}$ I investigate the learning-by-exporting hypothesis between exporting and productivity by applying the dynamic panel instrument approach from Kraay (1999) and matching technique developed by Becker and Ichino

\footnotetext{
${ }^{7}$ Firms' total factor productivity is used as the sole measure of firms' performance in this study.

${ }^{8}$ I only use data of five consecutive years from 1998 to 2002 for self-selection hypothesis investigation as data for this period contain the most continuously information on variables of interest.

${ }^{9}$ I adopt the De Loecker (2007) version and allow for export into the estimation to control for exporters specific unobserved productivity shocks and filter out common effects.
} 
(2002). The matching method allows me to use the propensity score matching technique to establish a control group to estimate the average treatment effects and identify the productivity premium from entering export market more accurately. I find that for five-year survivors the superior characteristics of Chinese exporters over Chinese non-exporters are large. I show that there is strong evidence supporting the self-selection hypothesis among Chinese exporters manufacturing firms. Comparing with their predate total factor productivities, I also find in most manufacturing industries that Chinese exporting entrants become more productive participating in the export market.

The remainder of the paper is organized as follows: in Section 1.1, I provide descriptive and preliminary analysis for Chinese manufacturing firms. In Section 1.2, I briefly talk about the main choices for estimating firm productivity and conduct the Ollay-Pakes productivity measure for Chinese manufacturing firms. In section 1.3, I test the self-selection hypothesis and learning-by-exporting hypothesis with the dynamic panel instrument approach and applying propensity score matching method.

\subsection{Data and preliminary analysis}

\subsubsection{Data description}

The Chinese firm-level survey is conducted by the Chinese Annual National Industrial Organization. The annual survey is given to a manufacturing establishment with yearly total sales of more than five hundred million yuan. Sales of the selected firms in the study account for $95 \%$ of total annual sales of all industrial firms in China. The dataset contains both qualitative and quantitative information of each 
firm for 29 industries for the 1998 - 2007 period. ${ }^{10}$ It is an unbalanced panel dataset with information on topics such as firm basic information (firm addresses, contact info, opening year, etc), ownership structure (private, state-owned, foreign), output value, sales, value added, expenses, assets, labor (head count and wages), market entry and exit, exports with entry and exit information, intermediate inputs, and financial accounting information. ${ }^{11}$ The key variable under investigation is the export status: at any point in time whether a firm is an exporter, a continuing exporter, a quitter or a domestic producer only. One must keep in mind that some firms may intentionally misreport manufacturing and financial information out of concern that government and tax authorities may gain access to the data and introduce troubles to the firm. However, since I assume such misreporting behavior is presented consistently overtime, the fixed-effect method in the analysis reduces such biased impact of over-reporting or under-reporting on my estimates.

I deflate data using the corresponding most disaggregated Producer Price Index (PPI) for constant prices. However, this method is not enough to control for the situation in which factor prices and output might be different and/or evolve differently over time for exporters.

Some key firm characteristics such as value added, R\&D, investment and detailed employment are either listed discontinued or are left blank for some years. Constructing propensity scores to match requires data with no missing values, for this reason I am forced to reduce the sample data from the original size to a sampled dataset which contains full information on 16,808 firms that operate nonstop

\footnotetext{
${ }^{10}$ The unit of observation is a single firm of a particular year. Each firm is assigned a unique identification code.

${ }^{11}$ Only firms that remain active in each of the consecutive years are taken into account.
} 


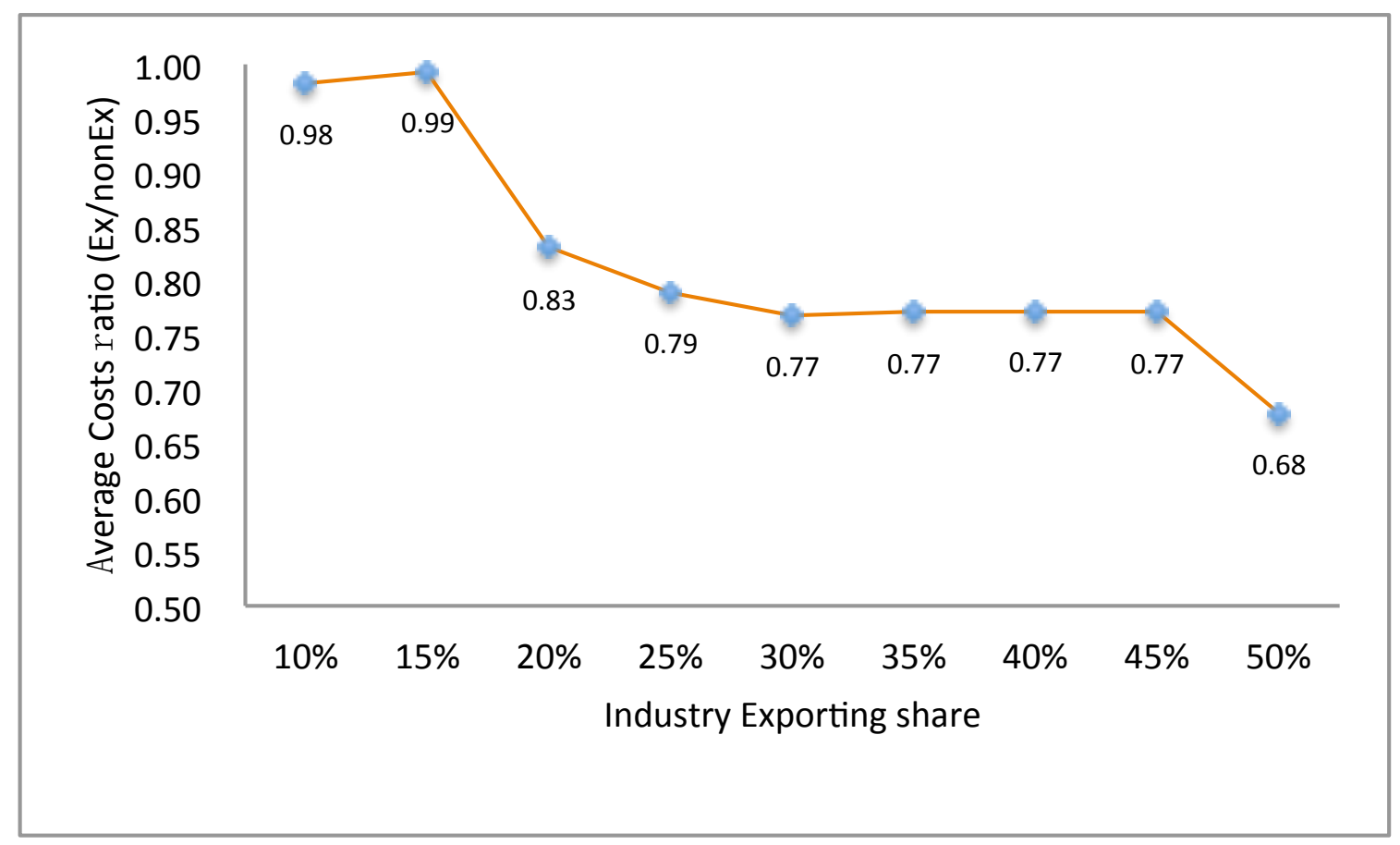

Figure 1.1: Average cost ratio between exporters and non-exporters

in years between 2001 and 2006. ${ }^{12}$ I divide the sample data into two groups based on export status of these firms. And I make sure all sample firms survive the entire sample period.

I define never-exporters as firms that never export during the sample period time. I choose exporters that begin exporting in year 2003 and onward. In addition, I make sure that all the selected firms do not export in first two sampled years. Furthermore, for the purpose of constructing a control group with significantly less noises I restrict exporters to continuous exporters only. As a result, the number of observations are reduced to 6,065 firms per sample year. Therefore, I am able to include sample firms of both types that operate in the entire sample period. Having two groups of these selected firms allows me to track firm productivity projectile throughout the sample period of time. I have no way of knowing whether firms

\footnotetext{
${ }^{12} 8,927$ when I restrict exporting firms that export no earlier than year 2003 firms.
} 


\begin{tabular}{ccccccccccc}
\hline & \multicolumn{2}{c}{ Investment } & \multicolumn{2}{c}{ Capital-labor ratio } & \multicolumn{2}{c}{ Employees } & \multicolumn{2}{c}{ Wages } & \multicolumn{2}{c}{ Inventories } \\
\cline { 3 - 11 } Year & Exp & Nonexp & Exp & Nonexp & Exp & Nonexp & Exp & Nonexp & Exp & Nonexp \\
\hline $2001-2002$ & $17.51 \%$ & $8.34 \%$ & $12.72 \%$ & $10.82 \%$ & $2.67 \%$ & $0.36 \%$ & $11.39 \%$ & $3.70 \%$ & $9.76 \%$ & $4.08 \%$ \\
$2002-2003$ & $25.64 \%$ & $21.92 \%$ & $5.58 \%$ & $3.16 \%$ & $5.72 \%$ & $1.43 \%$ & $19.76 \%$ & $7.98 \%$ & $20.36 \%$ & $12.34 \%$ \\
$2003-2004$ & $10.02 \%$ & $12.37 \%$ & $-7.59 \%$ & $3.58 \%$ & $4.20 \%$ & $-2.23 \%$ & $13.82 \%$ & $9.57 \%$ & $22.80 \%$ & $14.47 \%$ \\
$2004-2005$ & $-4.09 \%$ & $1.13 \%$ & $11.23 \%$ & $12.72 \%$ & $4.83 \%$ & $1.57 \%$ & $14.76 \%$ & $14.03 \%$ & $12.65 \%$ & $8.33 \%$ \\
$2005-2006$ & $41.00 \%$ & $6.15 \%$ & $25.38 \%$ & $14.40 \%$ & $0.87 \%$ & $-2.85 \%$ & $11.45 \%$ & $7.07 \%$ & $11.23 \%$ & $11.42 \%$ \\
\hline \multicolumn{2}{c}{} & & & & & & & & & \\
\hline Average & $18.02 \%$ & $9.98 \%$ & $9.46 \%$ & $8.94 \%$ & $3.66 \%$ & $-0.35 \%$ & $14.24 \%$ & $8.47 \%$ & $15.36 \%$ & $10.13 \%$ \\
\hline
\end{tabular}

Table 1.1: Summary statistics for exporters and non-exporters

that never exported in year 2001 and 2002 had any previous exporting experience. However, I assume they did not export in 2001 and 2002.

Figure 1.1 illustrates the average costs ratio of exports relative to those of nonexporters and their corresponding export shares. We can see that overall, Chinese exporters exhibit advantage in their average costs comparing with Chinese nonexporters. Such advantage becomes more prominent as the export share increases within the same industry. For example, Chinese manufacturing firms with 50\% export share are more than one third more efficient than the Chinese non-exporters operating within the same industry.

Table 1.1 presents the differences between exporters and non-exporters in the selected sample. It shows that potential exporters invest heavily prior to the entry into the export market, which seems to be in accordance with the aforementioned self-selection hypothesis. Table 1.1 also shows that three years after entering an international market, exporters expand production frontiers a lot faster than nonexporters to meet international demands. This can be seen from the fact that exporters increase investment by $40 \%$ relative to only $6 \%$ by non-exporters from year 2005 to year 2006. Table 1.1 indicates a similar level of the capital-labor ratio between exporters and non-exporters. The reason that capital-labor ratio does not differ that much in between exporters and non-exporters mainly comes from the fact 
that non-exporters are losing workers and that some capitals are left idled, indicating higher turnover rates for them and the possibility of switching to other industries due to tougher competition. On the contrary, exporters experience expansion in size and hire more workers. The increase in the wage for exporters is almost twice higher than that for non-exporters. One possible reason is the necessity to employ more high skilled workers relative to non-exporters, which in turn may result in

technology transfers. Another possible explanation is that workers in exporting firms ask for higher wages. Expecting to enter an export market, exporters increase more in holding inventories relative to non-exporters in the case of bigger demand in the international market, notably in year 2002 and 2003.

\subsubsection{Preliminary analysis}

In this subsection, I show statistically that exporters are different than non-exporters as shown in the relevant trade literature. Exporters are in general larger in size, pay higher wages, more capital-intensive and more productive than non-exporters. Examples include Aw and Hwang (1995), Bernard and Jensen (1995), (1997a), (1997b), (1997c), (1999), Roberts and Tybout (1996), Clerides, Lach and Tybout (1998), Castellani (2002), Wagner (2002), Greenaway and Kneller (2003), Alvarez and Lopez (2004), Van Biesebroeck (2006) and De Loecker (2007).

I run the following OLS regressions as shown in equation (1.1) to test for the exporter premia.

$$
\ln Z_{i t j}=\alpha+\beta E X P_{i t j}+\gamma \text { Control }_{i t j}+\mu_{i t j}
$$

where $Z_{i t}$ refers to the characteristics of firm $i$ at time $t$ active in industry $j, E X P_{i t j}$ is an export dummy variable equal to one when the firm $i$ is an exporter at time $t$ in industry $j$ and zero otherwise, and Control $_{i t j}$ is a vector of control variables con- 


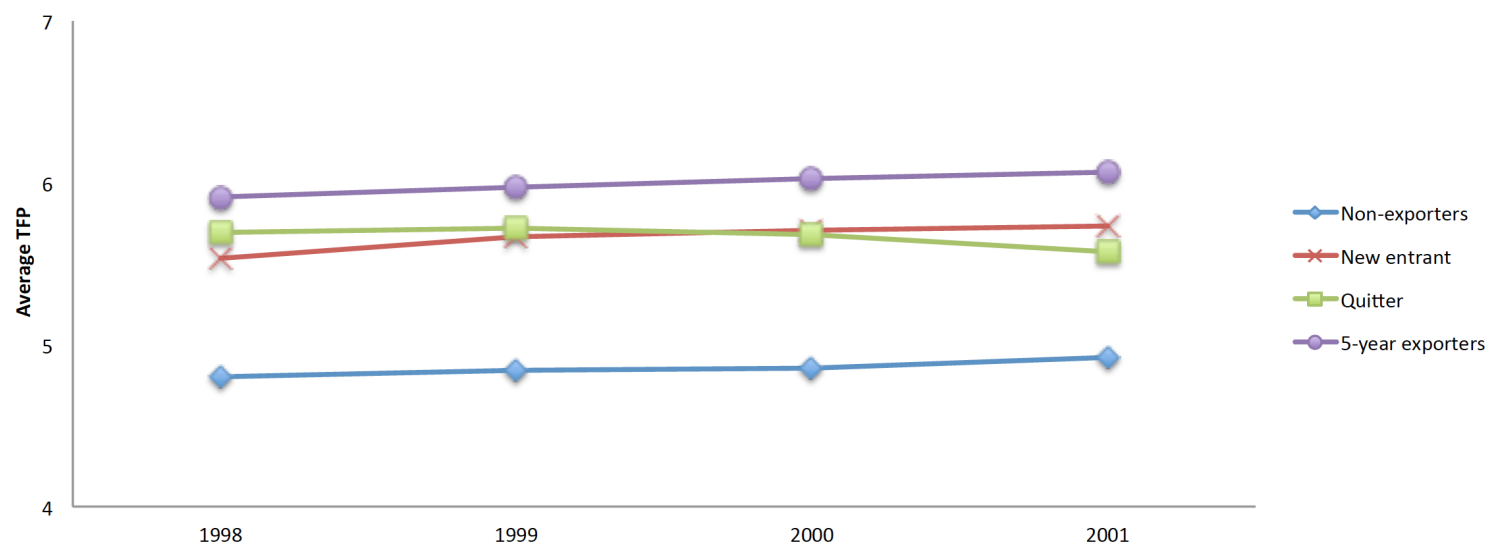

Figure 1.2: Productivity trajectories of grouped exporters and non-exporters

taining size effect (log of employment is used as a proxy for the size effect), industry effects (4-digit industry dummies), ownership effects (ownership dummies) and year effects (year dummies). Although my analysis focuses on individual industry, I also run equation (1.1) for the entire manufacturing sector to get a more comprehensive picture.

Table 1.2 shows the results of equation (1.1). According to the estimates, Chinese exporters are on average $30.43 \%$ more productive in terms of output per worker than Chinese non-exporters. ${ }^{13}$ Chinese exporters are also $9.23 \%$ more capital intensive relative to their domestic counterparts. In addition, Chinese exporters pay higher wages $(10.25 \%)$ and hire more $(32.55 \%)$ workers than non-exporting firms.

In Figure 1.2 I plot the total factor productivity trajectories of grouped exporters and non-exporters from 1998 to $2001 .^{14}$ Figure 1.2 confirms my finding that Chinese exporters in general have better performance in their average total factor productiv-

\footnotetext{
${ }^{13}$ Output per worker is calculated as a ratio of real output relative to numbers of employees. And it is also used as a proxy to labor productivity.

${ }^{14}$ I use year 2002 as the bench year. New entrants are firms that did not export in the first four years until year 2002; non-exporters are firms that did not export through out the five years; quitters are firms that exported in the first four years but quitted in the final year; and exporters are firms that exported for five years.
} 


\begin{tabular}{llll}
\hline Firm characteristic & Exporter dummy & $\mathrm{R}-\mathrm{sq}$ & Exporter premia \\
\hline \hline Output per worker & $\begin{array}{l}0.2657021^{* * *} \\
(0.0176665)\end{array}$ & 0.2203 & $30.43 \%$ \\
Capital per worker & $\begin{array}{l}0.0883159^{* * *} \\
(0.0228727)\end{array}$ & 0.0807 & $9.23 \%$ \\
Average Wage & $\begin{array}{l}0.1024925^{* * *} \\
(0.0120284)\end{array}$ & 0.7255 & $10.79 \%$ \\
Employment & $\begin{array}{l}0.3254859^{* * *} \\
(0.0191315)\end{array}$ & 0.0661 & $38.47 \%$ \\
\hline
\end{tabular}

Notes: Standard errors in parentheses. " $\mathrm{p}<0.05 " * * \mathrm{p}<0.01 * * * \mathrm{p}<0.001$.

Table 1.2: Firm characteristics differences between non-exporters and exporters

ities than Chinese non-exporters have. The continuous exporters have the highest average productivity from the beginning to the end and their productivity presents an upward trend. The non-exporters exhibit the lowest average productivity compared to the other three groups. New entrants and quitters appear to share similar levels of average productivity. This might indicate that new entrants managed to improve their performance prior to entering the export market and begin their first foreign sales. The average productivity of quitters starts to decline two years before officially quitting the export market. Although these results do not determine the causal relationship from performing good to exporting, Figure 1.2 provides further evidence for self-selection hypothesis and suggests that good Chinese firms become exporters.

Tybout (2003) and De Locker (2007) suggest that the decision to export could well have happened before the export sales records entering the database. This also seems to be the case for Chinese exporters. In Figure 1.3 I present a graphical framework to illustrate the overall total factor productivity trajectories of Chinese exporters and non-exporters.

In Figure 1.3 on the vertical axis I plot the average total factor productivity for two groups of firms under investigation: Chinese exporters and non-exporters. The 


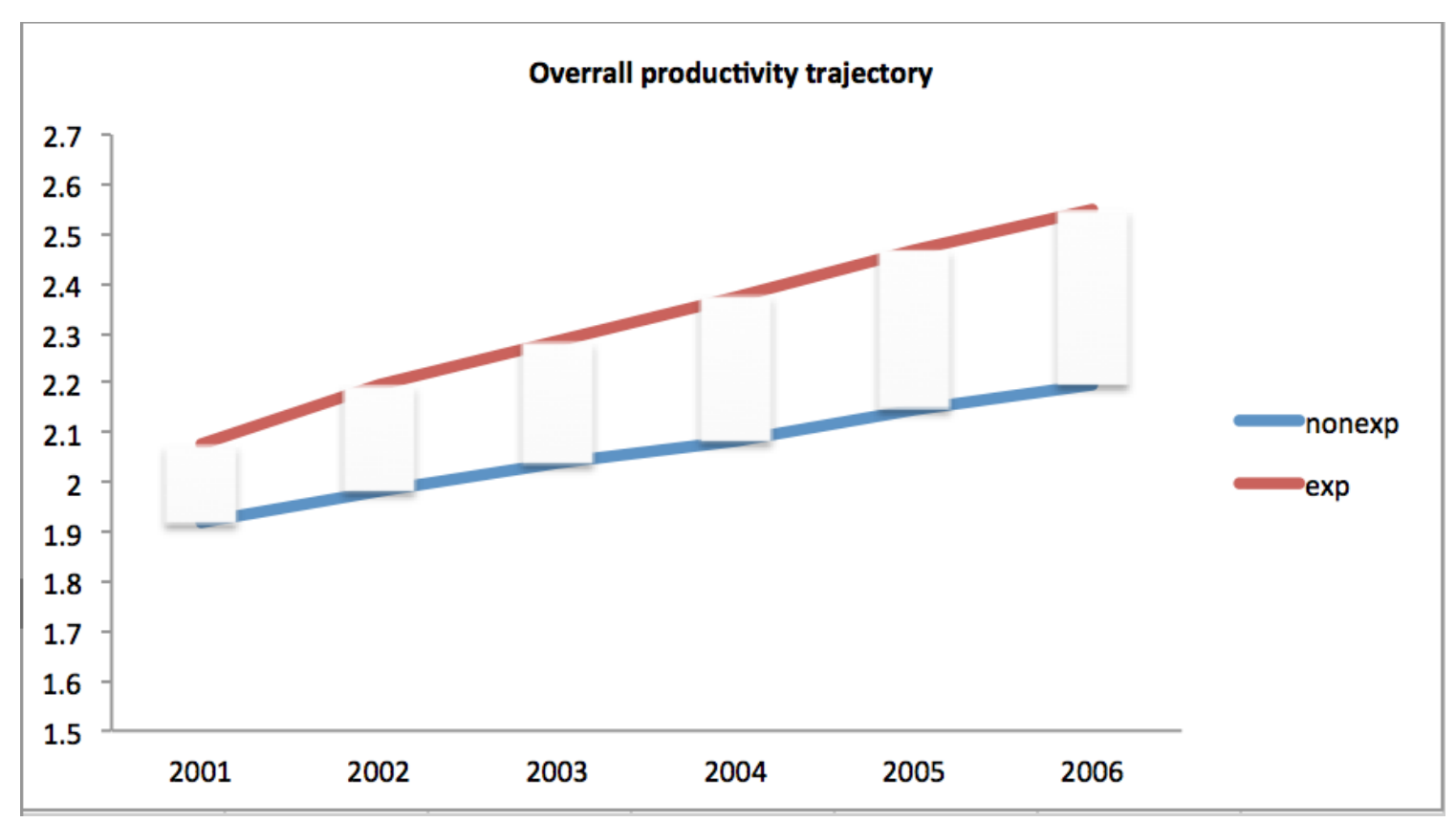

Figure 1.3: Overall Productivity Trajectory for non-exporters and exporters

selected starting year is 2001. For the first two years all firms are non-exporters and only sell in the domestic market until year 2003. In year 2003 exporting firms start to enter the export market. Figure 1.3 shows that Chinese exporters are already more productive than their domestic counterparts before entering the export market. Moreover, the productivity gap between exporters and non-exporters widens after the engagement in international market, suggesting a trace of evidence of learningby-exporting hypothesis of Chinese exporters.

\subsection{Productivity estimation}

Since the analysis is centered on firm productivity before-and-after exporting, reliable estimates of firm total factor productivity are required to obtain consistent results. There are various empirical methodologies presented in the trade literature as for how to estimate firm total factor productivity properly. Van Bieseberoeck 
(2007) summarizes and compares the robustness of five most frequently used estimating techniques: a) index numbers, b) eta development analysis (DEA), c) stochastic frontiers $(\mathrm{SF}), \mathrm{d})$ instrumental variables (GMM) and e) semi parametric estimation (Olley and Pakes, 1996). Each method has its unique strengths and weakness. ${ }^{15}$ Due to certain restrictions in the data, my choice of the total factor productivity estimation is based on Olley and Pakes (1996).

To estimate the total factor productivity for Chinese manufacturing firms using Ollay-Pakes methodology, I assume a production function for each Chinese manufacturing firm as follows: ${ }^{16}$

$$
Y_{i j t}=D\left(K_{i j t}, L_{i j t}, M_{i j t}, a_{i j t}, f_{i j}\right) e^{\omega_{i j t}+\epsilon_{i j t}}
$$

where $Y_{i j t}$ is the real gross output of the $i$ th firm in industry $j$ in year $t$, and $K_{i j t}$, $L_{i j t}, M_{i j t}, a_{i j t}$ and $f_{i j}$ are real capital, labor, firm age, intermediate inputs and firm specific fixed effects, respectively. ${ }^{17}$ Intermediate inputs include energy, materials and an estimate of purchased services. The term $e^{\omega_{i j}+\epsilon_{i j t}}$ is added to the production function to represent a productivity level that is unobservable to econometricians and a disturbance term that is assumed to be Independent and identically distributed (i.i.d). in each time period. The productivity shock is assumed as a state variable seen by the firm only and follows a Markov process unaffected by the firm's control variables.

\footnotetext{
${ }^{15}$ For further information about each method, please refer to Van Bieseberoeck (2007) for more technical details.

${ }^{16}$ I assume the same production function for each firm in every industry. I try to avoid biasing the results by pooling across industries with widely varying technologies so I assume the same technology within the same industry but allow technology to vary across different industries. By estimating coefficients for each firm in each industry, coefficients are allowed to vary.

${ }^{17}$ Allowing for firm fixed effects in time-series cross-sectional production will provide more explanation of the productivity distribution. (Baily, Hulten and Campbell, 1992.)
} 
For the purpose of estimating, I apply a log transformation to equation (1.2) to form the following translog production function:

$$
\begin{aligned}
\ln Y_{i j t}= & \beta_{0}+\beta_{1} \ln K_{i j t}+\beta_{2} \ln L_{i j t}+\beta_{3} \ln M_{i j t}+\beta_{4} a_{i j t}+\beta_{5} \ln ^{2} K_{i j t}+ \\
& +\beta_{5} \ln ^{2} L_{i j t}+\beta_{6} \ln ^{2} M_{i j t}+\beta_{7} a_{i j t}^{2}+\beta_{8} \ln K_{i j t} \ln L_{i j t}+ \\
& +\beta_{9} \ln K_{i j t} \ln M_{i j t}+\beta_{10} \ln K_{i j t} a_{i j t}+\beta_{11} \ln L_{i j t} \ln M_{i j t}+ \\
& +\beta_{12} \ln L_{i j t} a_{i j t}+f_{i j}+T+\omega_{i j t}+\epsilon_{i j t}
\end{aligned}
$$

where $T$ is a dummy variable for year $t$. The second-order logarithmic approximation of the production function places no functional form restrictions on the nature of return to scale. The total factor productivity is assumed as an unobserved plantspecific effect that can be estimated from a production function as the difference between real and predict values of firms' output. However, equation (1.3) cannot be consistently estimated by the OLS method as in reality more productive firms are more likely to export. In addition, firms can observe the productivity shocks (better managerial ability for example) that econometricians can not observe. These unobserved productivity shocks are included in the error terms hence tend to bias the estimates upwards. Moreover, firms with large capital stocks are more likely to survive the negative productivity shocks than firms with small size capital stocks. These small capital firms tend to self-select out of the market, therefore bias the estimates downwards. In order to get more consistent estimation results, both the simultaneity and the self-selection issue are needed to be controlled for.

I apply the Olley and Pakes (1996) three-stage estimation algorithm to control for aforementioned simultaneity bias and the selection bias in the estimation production functions. The residual of each estimation is used as the measure of the total factor productivity for each firm. 
The first stage regression equation is established as follows:

$$
y_{i j t}=\beta_{0}+\beta_{l} l_{i j t}+\beta_{k} k_{i j t}+\beta_{m} m_{i j t}+\beta_{a} a_{i j t}+f_{i j}+\omega_{i j t}+\epsilon_{i j t}
$$

where $y_{i j t}, l_{i j t}, k_{i j t}$, and $m_{i j t}$ are $\log$ values of the real output, real labor, real capital stock, and intermediate inputs; $a_{i j t}$ is the age of the firm; $f_{i j}$ is a firm specific fixed effect; $\omega_{i j t}$ is the productivity shock observed by the decision-maker but not by the econometrician; And $\epsilon_{i j t}$ is an i.i.d error term. Let $\tilde{\phi}_{t}\left(i_{i j t}, k_{i j t}\right)=$ $\beta_{0}+\beta_{k} k_{i j t}+\beta_{a} a_{i j t}+h_{t}\left(i_{i j t}, k_{i j t}\right) . h_{t}\left(i_{i j t}, k_{i j t}\right)$ is used to control for simultaneity problem. ${ }^{18}$ Since the functional form of $\tilde{\phi}_{t}\left(i_{i j t}, k_{i j t}\right)$ is not known the coefficients $\beta_{l}$ and $\beta_{k}$ are estimated by proxying a functional form for $\tilde{\phi}_{t}\left(i_{i j t}, k_{i j t}\right)$ using a secondorder polynomial expansion in variables of choice as well as instrumental variables. ${ }^{19}$ The first stage provides unbiased estimates for labor.

The second stage is used to control for the self-selection problem and achieved so by regressing lagged variables of choices on the binary exit variable $e^{x i t} t_{i j t}$. The second stage estimating function is defined as follows:

$$
P\left(e_{i j t} i_{i j t}=1 \mid I_{t}\right)=P\left[\operatorname{exit}_{i j t}=1 \mid \underline{\omega}_{i j t-1}\left(I_{i j t-1}, k_{i j t-1}, a_{i j t-1}\right)\right]
$$

where exit ${ }_{i j t}$ is the dummy variable for the an exit firm; and $\underline{\omega}_{i j t-1}$ is a specific state variable. Whether a firm chooses to stay in the market depends on its total factor productivity $\omega_{i j t-1}$, and in turn on the firm's age, capital stock, and investment level at time $t-1$. The probability of survival is examined by fitting a probit model on investment level at time $t-1 I_{i j t-1}$, capital stock at time $t-1 k_{i j t-1}$, firm age at time $t-1 a_{i j t-1}$ and on instrument variables.

\footnotetext{
${ }^{18} h_{t}\left(i_{i j t}, k_{i j t}\right)$ is the inverse function of the investment function, assuming a strictly increase relationship between productivity shock $\omega_{i j t}$ and the investment $i$.

${ }^{19}$ Interaction terms between labor and capital, intermediate inputs and capital stocks, capital stocks and firm age, firm age and intermediate inputs, and squared individual terms.
} 
The third stage is an additional step used to control for the self-selection problem and to acquire consistent estimates for capital stock and firm age. In the third step, I fit the following equation by a nonlinear least square function:

$$
\begin{aligned}
y_{i j t}-\beta_{l} l_{i j t}-\beta_{m} m_{i j t}= & \beta_{k} k_{i j t}+\beta_{a} a_{i j t}+ \\
& +g\left(\hat{\phi}_{t-1}-\beta_{k} k_{i j t-1}-\beta_{a} a_{i j t-1}, \hat{P}_{i j t}\right)+ \\
& +f_{i j}+\omega_{i j t}+\epsilon_{i j t}
\end{aligned}
$$

With consistent labor and capital estimates obtained using these three steps, I establish the total factor productivity proxy or the residual by calculating the following equation:

$$
\Omega_{i j t}=e^{\left(y_{i j t}-b_{l i j} l_{i j t}-b_{k i j} k_{i j t}-b_{a i j} a_{i j t}-b_{m i j} m_{m i j}\right)}
$$

Please note that these estimated total factor productivities are firm-specific and time-varying since I do not assume the same technology across industries for each individual firm.

\subsection{Econometric models}

\subsubsection{Test the self-selection hypothesis}

In this subsection, I further investigate the self-selection hypothesis using an econometric model developed by Bernard and Jensen (1999). According to Bernard and Jensen (1999), a firm exports only when current and future expected revenues exceed

costs. $^{20}$ I use the proposed binary choice non-structural econometric model to estimate for self-selection hypothesis. And the suggested binary equation is established as follows:

$$
\text { Export }_{i t}=\alpha_{i}+\beta X_{i t-1}+\gamma \text { Export }_{i t-1}+\psi_{i}+\mu_{i t}
$$

\footnotetext{
${ }^{20}$ Entry costs are sunk and included.
} 
Dependent variable: exporting status

\begin{tabular}{lcccc}
\hline \multicolumn{1}{c}{ First difference } & \multicolumn{2}{c}{ Dummy variables } \\
\hline \hline Firm characteristics & Coefficients & Year & 4-digit SIC & Ownership \\
Total factor productivity & $0.0006102 * * *$ & & & \\
Wage & $(0.0000177)$ & & & \\
& $0.0197568 * * *$ & & & Yes \\
Employment & $(0.0007005)$ & Yes & Yes & \\
& $0.0153912 * * *$ & & & \\
Previous exporting status & $(0.0005256)$ & & & \\
& $-0.4980548 * * *$ & & & \\
\hline
\end{tabular}

Notes: Standard errors in parentheses.

"p $<0.05 " * * \mathrm{p}<0.01 * * * \mathrm{p}<0.001$.

Table 1.3: Firms' decision to export

where Export Ex $_{i t}$ is an export dummy variable for firm $i$ in year t. $X_{i t-1}$ is firm characteristics such as total factor productivity, size (log of employment) and human capital (log of wage). One period lagged variables are used to reduce possible simultaneity issues. And $X_{i t-2}, X_{i t-3}$, Export $_{i t-2}$ and Export $_{i t-3}$ are used as instruments. The variable $\psi_{i}$ is included to reflect the unobserved firm heterogeneity such as proprietary technology. Control variables are included in the regression to control for fix effects. ${ }^{21}$ The actual estimation is done by using the first-difference form of equation (1.9) to get more consistent estimators. The first-difference form of equation (1.9) is presented as follows:

$$
\Delta \text { Export }_{i t}=\beta \Delta X_{i t-1}+\gamma \Delta \text { Export }_{i t-1}+\Delta \mu_{i t}
$$

Table 1.3 reports the coefficients of firm characteristics results from equation (1.9), which is the first-difference linear probability model.

All results are significant at $1 \%$ level. I find that total factor productivity, wage and employment are positively related to the probability of exporting. A $10 \%$ in-

\footnotetext{
${ }^{21}$ Full sets of year dummies, 4-digit industry dummies and ownership dummies are included in the model.
} 
crease in productivity results in a $0.006 \%$ increase in the probability of exporting. This suggests that a higher productivity does tend to lead to higher exporting probability. For a $10 \%$ increase in wage, the probability of exporting goes up by $0.198 \%$, whereas a $10 \%$ increase in employment results in a $0.154 \%$ increase in the probability of exporting. Therefore, the pattern revealed in this regression is that all productivity, wage and employment play important and positive roles in the determination of entering into the export market.

Another interesting result lies in the estimate for previous exporting status. The negative relationship between the first difference and the exporting status means that once the firm enters or exits the export market, it is less likely that the situation will be reversed. In other words, the chance for the firm to re-enter the export market is decreased once the firm is driven out of the export market. Table 1.3 shows quantitatively that if a firm leaves the export market last year, the probability to come back to export market in next year decreases by $4.98 \%$. Likewise, if a firm exported last year, the probability of the firm to exit the export market during the next year falls by $4.98 \%$. And this result is generally taken as evidence of the presence of sunk entry costs to the export market.

\subsubsection{Propensity score and matching}

I show in the last subsection that the average performance of Chinese exporters is better than Chinese non-exporters. However, the comparison of average performance between exporters and non-exporters does not reveal any causal effects of exporting activities on the the performance of Chinese exporting firms.

Having biased estimates using a firm-level dataset is unavoidable since it is observed data entry and does not come from randomized lab trials. Therefore, I use 
the propensity score matching method proposed by Rosenbaum and Rubin (1983) to reduce the bias in the estimation of treatment effects with the observational Chinese firm-level dataset. To do so, I construct a control group for the designed treatment group as a quality control group is crucial for the propensity score matching method to take effect sufficiently good. ${ }^{22}$

I define the propensity score as the conditional probability of exposure to a treatment (exporting, denoted as $E X P=1$ ) given pretreatment firm characteristics:

$$
p(X) \equiv \operatorname{Prob}(E X P=1 \mid X)=E(E X P \mid X)
$$

where $X$ is the multidimensional vector of pretreatment firm characteristics and $E X P$ is the treatment (exporting). After acquiring the propensity score $(p(X))$, the causal effect of exporting on the total factor productivity can be estimated as follows: $:^{23}$

$$
\begin{aligned}
E\left\{y^{1}{ }_{i t}-y_{i t}^{0} \mid E X P_{i t}=1\right\}= & E\left[E\left\{y_{i t}^{1} \mid E X P_{i t}=1, p\left(X_{i}\right)\right\}-\right. \\
& \left.\left.-E\left\{y^{0}{ }_{i t} \mid E X P_{i}=0, p\left(X_{i t}\right)\right\} \mid E X P_{i t}=1\right\}\right]
\end{aligned}
$$

where $y^{1}{ }_{i t}$ denotes the outcome (the total factor productivity) of firm $i$ in period $t$, and $y^{0}{ }_{i t}$ is the outcome of firm $i$ had it not exported. The binary variable $E X P_{i t}$ takes on the value 1 if firm $i$ exports at period $t$ and zero otherwise.

Given the assumption that firms of the same cell exposed to exporting activity is random, the treatment of exporting acts as an exogenous shock from outside. As the treatment happens, treated firms 'automatically' export by design. As opposed to self-select themselves into export market, exporting firms of all firms in the same

\footnotetext{
${ }^{22}$ As Becker and Ichino (2003) stress, the propensity score matching program is to reduce instead of eliminate the bias generated by unobservable confounding factors.

${ }^{23}$ As Becker and Ichino (2003) states, treatment units and control units should be on average observationally identical given the assumption that exposure to treatment (exporting) is random.
} 
cell are randomly selected to export, and the rest (the control firms) have the equal probability of being chosen but for some reasons are not selected. This mechanism has little if nothing to do with the proposed self-selection hypothesis that suggests more productive firms' self-selection into the export market. I adopt the proposition by Hallward-Driemeier, Iarossi and Sokoloff (2002), which states that it is in aiming for the export market for higher profit opportunities that firms increase their total factor productivities. I treat firms in each cell as exporting ready since they are assumed done with the improvements in various core firm characteristics. The treatment now can be treated as the export quota. Firms in the same cell have equal probabilities of given a permission to export.

However, there is a key problem in equation (1.11), which is that $y^{0}{ }_{i t}$ is not observable in the data. I construct a counterfactual for the term $y^{0}{ }_{i t}$ that represents outcomes (total factor productivities) that firms would have experienced in the export market had they not engaged in the export market. A valid control group among non-exporters is needed as the goal is to find a group in which the distribution of the variables affecting the outcome variables is as close as possible to the exporting firm in terms of its predicted probability to exporting. I assume that all differences between exporters and the appropriately selected control group are acquired by a vector of observables representing characteristics of firm $i$ including the pre-export total factor productivity. The difference excludes the impact caused by export activities. I use a probit model with a dependent variable equal to 1 if a firm starts exporting and 0 elsewhere on lagged observables and higher order polynomial terms. And the proposed probit model is established as follows:

$$
p\left(E_{X X} P_{i t}=1\right)=F\left\{h\left(T F P_{i-1}, \text { capital }_{i t-1}, \text { humancapital }_{i t-1}, \text { size }_{i t-1}, \text { age }\right)\right\}
$$


where $\mathrm{F}$ function in equation (1.12) is the normal cumulative distribution function. I include a full set of year dummies to control for common aggregate shocks. I take a full polynomial in the elements of $h($.$) to improve the matching, thus freeing up the$ functional form as shown in Woolbridge (2002) and De Locker (2007). The difference in productivity is thus conditioned on pre-export levels of productivity, capital, human capital (proxied by wages), firm size (proxied by number of employees), firm age, and other relevant firm-level covariates.

Before estimating the propensity score, I test the Balancing Hypothesis for equation (1.12). I run the following algorithm: (i) split the sample into $k$ equally spaced intervals intervals of the propensity score $p_{i t}$ and test within each interval that the average $p_{i t}$ of treated and control units do not differ, (ii) within each interval test that the means of each characteristic do not differ between treated and control units. If the balancing property is not satisfied a less parsimonious specification of $h($.$) is$ needed. ${ }^{24}$ For different industries, the effects of covariates on the probability to export may differ across different sectors due to different technology and market shocks. I run estimates for each industry separately to obtain the probability to export of each firm. This method is less restrictive as opposed to estimation for the entire manufacturing sector.

In principle, the probability of observing two firms with exactly the same value of a propensity score is impossible since $p(X)$ is a continuous variable. To overcome this problem, I choose the Nearest-Neighbor Matching method. ${ }^{25}$ Let $p_{i t}$ denote

\footnotetext{
${ }^{24}$ For technical details please refer to Becker and Ichino (2002).

${ }^{25}$ It should be noted that the nearest neighbor may have a very distinctive $p(X)$ so the match can be very poor. Nevertheless, such matching would contribute to the estimation of the treatment effect regardless of the difference. (Becker and Ichino, 2003).
} 
the the predicted export probability for firm $i$ at time $t .{ }^{26}$ A non-exporting firm $j$ is selected in terms of its propensity score closest to that of a exporting firm as a match for the exporting firm. The set of control units matched to the treated unit $i$ with an estimated $p(X)$ is stated as follows:

$$
\operatorname{Control}(i t)=\left|p_{i t}-p_{j t}\right|=\min _{j}|| p_{i t}-p_{j t}||
$$

I conduct the matching process for each 3-digit SIC manufacturing sector. The control groups are therefore constructed within narrowly defined sectors. Nearestneighbor matching indicates that only a subset of the sample of each industry is used to estimate. ${ }^{27}$

\subsubsection{The average effect of treatment on the treated}

I rewrite Control(it) as $C(i t)$. Variables $Y^{t}$ and $Y^{c}$ are the estimated total factor productivities of the treated sample and the controls, respectively. Assuming $N_{t}^{E}$ firms exporting at time $t$ and the number of control units as $N_{i}^{c}$, then the weight is defined as $w_{i j}=\frac{1}{N_{i}^{c}}$. I then estimate the productivity difference of treated firms that export at each period $t$ compared with a weighted average of productivity of a control unit at each period $t$ based on nearest-neighbor method. The average effect of treatment on the treated or the learning-by-exporting effect denoted as $\beta_{L B E}$ can be estimated as follows:

$$
\beta_{L B E}=\frac{1}{N_{t}^{E}} \sum_{i \in T}\left(Y_{i t}^{1}-\sum_{j \in C(i)} w_{i j} Y_{j t}^{c}\right)
$$

\footnotetext{
${ }^{26}$ For convenience I rewrite $p\left(E X P_{i t}\right)$ as $p_{i t}$.

${ }^{27}$ The sample is reduced drastically due to the imposing of the common support restriction.
} 
And the corresponding variance is calculated using the following equation:

$$
\operatorname{Var}\left(\beta_{L B E}\right)=\left(\frac{1}{N_{t}^{E}}\right)^{2}\left\{\sum_{i \in T} \operatorname{Var}\left(Y_{i t}^{1}\right)-\sum_{j \in C(i)}\left(w_{i j}\right)^{2} \operatorname{Var}\left(Y_{j t}^{c}\right)\right)
$$

\subsubsection{Estimated results}

In the last subsection I use a logit model based on equation (1.12) to estimate propensity scores for firms in the same industry; I test for theBalancing Hypothesis for each propensity score estimated; and I construct control units for each individual industry and account for all fixed effects. Table 1.4 summarizes my findings for the manufacturing sectors that satisfy the Balancing Hypothesis. Column (ii) shows the average impact of exporting on the level of total factor productivity at every period of time $t$. Column (ii) presents a average change in productivity growth rate in each period $t$ as a result of exporting. I also list the number of treated and control units that are being matched together based on the estimated propensity scores. ${ }^{28}$

I find some evidence in various Chinese manufacturing industries that support the learning-by-exporting hypothesis according to Table 1.4. Over the selected years of exporting, Chinese exporters grow faster and perform better than in pre-export era in terms of their total factor productivity. Chinese exporters also perform better in terms of total factor productivity than their domestic counterparts.

The positive treatment effects on the level of total factor productivities are statistically significant on the total factor productivity outcome for the following industries: the non-metal industry with 8.1 percentage points increase, the textile industry with 9.3 percentage points increase, the pharmaceutical industry with 14.5 percentage points increase, and the plastics manufacturing industry with 10.4 per-

\footnotetext{
${ }^{28}$ Notice that the number of treated and controls has decreased dramatically for both treated units and control units due to the implementation of Nearest Neighbor matching.
} 
centage points jump. The textile industry is the only industry that is statistically significant at a $5 \%$ level, the rest of the three industries are significant at $10 \%$ levels. The positive treatment effects are statistically significant on the growth rate of total factor productivity outcome for the following industries: the paper industry with 3.8 percentage points increase, the non-metal industry with 4 percentage points increase, the primary metal industry with 14.5 percentage points increase, the fabricated metal industry with 5.1 percentage points increase, the general equipment industry with 3.5 percentage points increase, and the office supplies industry with 5.3 percentage points increase. Only the general equipment industry is statistically significant at the $5 \%$ level and the rest of the listed industries are significant at the $10 \%$ level. Although the results are not statistically significant, negative treatment effects present in a few industries on both the productivity and growth rate of the productivity outcomes. Examples are both outcomes for the apparel industry, the productivity outcome for the paper industry and the productivity outcome for general equipment industry. In addition, industries like food processing, apparel, chemicals, transportation equipment and electrical equipment do not exhibit statistically significant results. In fact, the apparel industry shows negative impacts of exporting activity on both outcome variables.

Overall, these growth rates of total factor productivity are found to be positively associated with gains in corresponding levels of total factor productivities. Meaning the two outcome variables under study move in the same direction giving treatments. However, these estimated results show that Chinese exporters of the manufacturing sector do not across the board significantly improve in terms of their performance or total factor productivity faster than Chinese non-exporters of the same sector by participating in the export market; The food processing industry, apparel and 


\begin{tabular}{|c|c|c|c|c|c|}
\hline \multirow{2}{*}{ SIC } & \multirow{2}{*}{ Industry } & \multicolumn{2}{|r|}{ Outcome } & \multicolumn{2}{|c|}{ Number of } \\
\hline & & (i) Productivity & (ii) Productivity growth & Treated & Controls \\
\hline 13 & Food processing & $\begin{array}{l}-0.009 \\
(0.070)\end{array}$ & $\begin{array}{c}0.014 \\
(0.031)\end{array}$ & 142 & 127 \\
\hline 17 & Textile & $\begin{array}{l}0.093 * * \\
(0.044)\end{array}$ & $\begin{array}{l}0.014 \\
(0.019)\end{array}$ & 269 & 226 \\
\hline 18 & Apparel & $\begin{array}{l}-0.008 \\
(0.079)\end{array}$ & $\begin{array}{l}-0.009 \\
(0.039)\end{array}$ & 99 & 74 \\
\hline 22 & Paper & $\begin{array}{l}-0.053 \\
(0.115)\end{array}$ & $\begin{array}{l}0.038^{*} \\
(0.030)\end{array}$ & 71 & 67 \\
\hline 26 & Chemicals & $\begin{array}{l}-0.037 \\
(0.052)\end{array}$ & $\begin{array}{l}0.003 \\
(0.017)\end{array}$ & 184 & 171 \\
\hline 27 & Pharmaceutical & $\begin{array}{l}0.145^{*} \\
(0.099)\end{array}$ & $\begin{array}{l}0.056 \\
(0.067)\end{array}$ & 53 & 45 \\
\hline 30 & Plastics & $\begin{array}{l}0.104^{*} \\
(0.061)\end{array}$ & $\begin{array}{l}0.067 \\
(0.027)\end{array}$ & 120 & 100 \\
\hline 31 & Non-metal & $\begin{array}{l}0.081^{*} \\
(0.053)\end{array}$ & $\begin{array}{l}0.040^{* * *} \\
(0.016)\end{array}$ & 296 & 259 \\
\hline 32 & Primary metal & $\begin{array}{c}0.160 \\
(0.167)\end{array}$ & $\begin{array}{l}0.145^{*} \\
(0.081)\end{array}$ & 52 & 42 \\
\hline 34 & Fabricated metal & $\begin{array}{l}0.062 \\
(0.057)\end{array}$ & $\begin{array}{l}0.051^{*} \\
(0.032)\end{array}$ & 95 & 85 \\
\hline 35 & General equipment & $\begin{array}{l}-0.001 \\
(0.033)\end{array}$ & $\begin{array}{l}0.035^{\text {** }} \\
(0.017)\end{array}$ & 267 & 228 \\
\hline 37 & Transportation equipment & $\begin{array}{l}0.060 \\
(0.047)\end{array}$ & $\begin{array}{c}0.014 \\
(0026)\end{array}$ & 176 & 150 \\
\hline 39 & Electrical equipment & $\begin{array}{l}-0.016 \\
(0.050)\end{array}$ & $\begin{array}{l}0.028 \\
(0.022)\end{array}$ & 238 & 201 \\
\hline 41 & Office supplies & $\begin{array}{l}0.026 \\
(0.075)\end{array}$ & $\begin{array}{l}0.053^{*} \\
(0.031)\end{array}$ & 52 & 42 \\
\hline
\end{tabular}

Notes: (i) The algorithm is restricted to the common support for each propensity score.

The number of treated and control units decreases.

(ii) Standard errors in parentheses. " $\mathrm{p}<0.05 " * * \mathrm{p}<0.01 * * * \mathrm{p}<0.001$.

(iii) A full set of time dummies is included.

Table 1.4: Estimated learning-by-exporting effects for selected industries 
nonferrous metal industry and electrical equipment, for example, all show negative treatment effects on their outcomes.

\subsection{Conclusion}

Using the Chinese manufacturing firm-level dataset, I construct the total factor productivity as the performance measure of a firm by applying the Ollay-Pakes productivity methodology for Chinese manufacturing firms. The first difference estimation results provide evidence for the self-selection hypothesis and suggest that better Chinese firms enter the export market. I then test the learning-by-exporting hypothesis with dynamic panel instrument approach and applying propensity score matching. I also find in various manufacturing industries that Chinese exporting entrants become more productive by participating in the export market . 


\section{CHAPTER 2}

\section{INTRODUCTION}

Firms that aim to expand their businesses internationally often face the same question: should they invest in plants that can manufacture and sell goods locally in selected host countries or should they sell their products to overseas consumers while manufacturing in their domestic factories? This paper tackles the aforementioned fundamental dilemma facing these firms by asking the following question: how should domestic firms choose their international expansion strategies given two strategic options which are the horizontal foreign direct investment (FDI) and export, respectively? I try to establish relationships between export and foreign direct investment as alternative modes of international expansions by building a theoretical model first and testing it with a carefully crafted econometric model.

I restrict foreign direct investment strategy to the local market oriented horizontal FDI and comply with the established FDI definition presented in the relevant trade literature. According to the definition, horizontal FDI refers to investments in overseas production facilities that are built to serve only local consumers in the host country. Investing abroad requires mandatory sunk costs to build foreign plants, whereas the export strategy involves in unavoidable trade costs such as transport costs and tariffs. I assume the iceberg type per unit trade cost as the sole form of the trade cost. A firm chooses to invest in a foreign country when gains from avoiding trade costs surpass costs required to maintain the capacity in the same host market (Helpman, 2003). For this reason, the firm has an incentive to engage in the FDI strategy instead of exporting.

In this study, I develop a simple theoretical model to explore: 1) how firms make investment decisions on expansionary strategies into international market by choosing between horizontal FDI and export; and 2) the effect of the change in 
consumers' income distribution of the foreign country on these firms' international expansion decisions. I utilize a specially designed mean-preserving income distribution and investigate the strategy of producing abroad versus the alternative strategy of exporting by comparing market demand before and after the change in income dispersion or concentration determined by a spreading parameter of the chosen income distribution function. ${ }^{1}$ I assume a fixed foreign market size. The change in market demand comes from the change in consumers' personal income levels hence the income distribution. The change in market demand affects aggregate revenues and aggregate profits earned by entered firms. This effect in turn allows me to establish a connection between the change in income distribution and firms' profitability.

One of the underlying assumptions in my investigation is that each consumer has demand for one and only one unit for a reservation price less than or equal to his or her valuation of a consumption good and zero units for any prices above such reservation price. I assume that each consumer's valuation of a product is directly related to his or her income level, therefore a consumer's reservation price is proxied by his or her income.

As the trade and FDI literature suggests, many factors affect firms' productionlocation decisions. My study does not consider such case in which factor supplies affect production-location decisions as they do in vertical integration models motivated by differentials in factor costs and intensities. Instead, I address the relationship between exporting and producing overseas as alternative modes of foreign-market penetration by domestic or multinational firms taking into account the income distribution of the foreign market. This means that I explore the extent to which a trade-off between multinational production-location decisions, namely maximizing

\footnotetext{
${ }^{1}$ I assume a mean-preserving income distribution in a sense of the second order stochastic dominance. When the distribution changes its mean value remains the same.
} 
proximity to customers by manufacturing abroad through horizontal FDI and/or achieving scale economies by producing at home, can be explained by the distributional change in consumers' income.

Lambert and Pfahler (1997) study the effect of distributional changes on the size of the market for a certain price level via the shape of the consumers' Engel curves. Benassi, et al (2002) demonstrate that the concentration in the middle class leads to a more elastic market and a relevant segment of demand expanding, which explains the phenomenon that markets patronized by richer consumers benefit from the middle class entering because of the corresponding bigger market size and lower prices.

Whether export and FDI are substitutes or complements is a heated debate in the rich and ongoing trade and FDI literature and often leads to conflicting findings in relevant research. Many empirical works attempting to tackle this issue struggle to find solid evidences that support the proposition of FDI and exporting as alternative strategies. However, some empirical research such as Swedenborg (1979) and Blomstrom et al.(1988) regarding multinationals find that exports and multinational sales in foreign markets complement one another.

Using gini coefficient as a proxy for the income distribution dispersion, I am able to partially test the theoretical model by developing an econometric model with fixed effects. I assume that well established factors such as internal aspects and external components as potential determinants of FDI and/or export besides profits after sales are given. I also omit the other factors such as exogenous and policy factors that might affect the magnitude of FDI. These factors are controlled for by country-level and industry-level fixed effects. In addition, I distinguish trade between intra-industry trade and non-intra-industry trade hoping to eliminate the con- 
cern that affiliate sales and exports are complements. ${ }^{2}$ Furthermore, I address the possible simultaneity problems between affiliate productions and exports through taking into account the following factors: exchange rates, internalization, corporate taxes, tariffs, transport costs and institution quality. The trade and FDI literature shows that these factors may also affect multinationals' decision making on international expansion. Brainard (1997) finds support for the internalization hypothesis. Horst (1972) finds that both affiliate production and exports are increasing in R\&D intensity. Harrigan (1993) finds that trade flows are decreasing in tariff levels. Anderson (1979) and Bergstarad (1985) show that transport costs raise the delivered price of imports to consumers. Brainard (1997) finds that affiliate production rises as a share of total foreign sales the greater are transport costs and foreign trade barriers.

The remainder of the paper is organized as follows: in Section 2.1, I discuss the choice of and model the income distribution, and establish the relationship between the income distribution, market demand and price. In Section 2.2 and the subsequent subsections, I introduce horizontal foreign direct investment (FDI) and export as alternative strategies for expanding internationally and discuss different case scenarios in which firms make decisions on international investments based on profitability. In section 2.3 and its subsections, I develop an empirical model with fixed effects and use the chosen FDI and trade data to test the theoretical model.

\footnotetext{
${ }^{2}$ Intra-industry trade is trade between multinational firms headquarters and their foreign affiliates.
} 


\section{$2.1 \quad$ Model}

\subsubsection{Modeling the income distribution}

Consumers' heterogeneity is an important element in explaining market behaviors. In this investigation I study consumers' income heterogeneity and model this heterogeneity by choosing a mean preserving income distribution in a sense that an increase in the mean preserving parameter can be viewed as an increase in income dispersion that leaves the average income unchanged. I assume that consumers have the same preferences but differ only in their incomes.

The reason that I model the distributive shifts in consumers' income levels in the form of mean preserving changes is that these changes in the income distribution can be thought of as the widely known phenomena of income polarization and shrinking of rising middle class, which have characterized many countries in both the developed and developing world over the last two decades.

I model the mean preserving income distribution with a continuous differentiable unimodal density function denoted as $f(I, \alpha)$, defined over some positive interval $I_{\min }<I<I_{\max }$. Variable $I$ represents consumers' income levels with $I_{\min }$ and $I_{\max }$ being the corresponding minimum value and the maximum value in the interval, respectively. The parameter $(\alpha)$ serves as the desired mean preserving spread that drives my analysis. I define the following rule for the mean preserving parameter $(\alpha)$ : a change in the mean preserving parameter $\alpha$ results in the change in the spread of the income distribution while leaving the mean income intact.

I denote $\bar{I}$ as the modal income of the mean preserving income distribution. The cumulative density function of the income distribution can be established as $F(I, \alpha)=\int_{I_{\min }}^{I_{\max }} \mathrm{f}(\mathrm{x}, \alpha) \mathrm{d} x$. And the corresponding density function $f(x, \alpha)$ of the 
income distribution has the following properties:

$$
\begin{cases}\frac{\partial f(I, \alpha)}{\partial \bar{I}}=0, & \text { if } I=\bar{I} \\ \frac{\partial f(I, \alpha)}{\partial \bar{I}}>0, & \text { if } I<\bar{I} \\ \frac{\partial f(I, \alpha)}{\partial \bar{I}}<0, & \text { if } I>\bar{I}\end{cases}
$$

The corresponding cumulative density function (CDF) and probability density function graphs of the income distribution can have complicated shapes. The CDFs can intersect multiple times as long as $\frac{\partial F^{1}(I, \alpha)}{\partial \alpha}$ starts out flatter than $\frac{\partial F^{2}(I, \alpha)}{\partial \alpha}$ and the gap between areas under the two CDFs does not close entirely until the end-point $I_{\max } \cdot{ }^{3}$

To ease computation of my theoretical model without great loss of generality, I impose some necessary conditions on the CDF of the income distribution $F(I, \alpha)$. First, an increase in the mean preserving spread parameter $(\alpha)$ is defined as shifting pairs of probability weights on either side of the mean farther away, while leaving the mean value unchanged. Second, CDFs of income distributions only intersect once in between the starting point $\left(I_{\min }\right)$ and the end-point $\left(I_{\max }\right)$ so it is of a simple type by Rothschild and Stigliz (1971).

To get a better idea about these assumptions, I show a concrete example for each CDF, density function and $F_{\alpha}(p, \alpha)$ function of such mean preserving income distribution in Figure 2.1.

I divide the density function and the partial derivative of the CDF function $F_{\alpha}(I, \alpha)$ into four intervals as shown in the third graph of Figure 2.1 in the spirit of Benassi, et, al (2002). The previously specified conditions on the distribution make it easy to summarize some properties of the effect of the change in the mean preserving spread parameter $(\alpha)$ on each distribution and allow me to identify the sign of each

\footnotetext{
${ }^{3}$ Superscripts represent the numbering of the two distributions.
} 

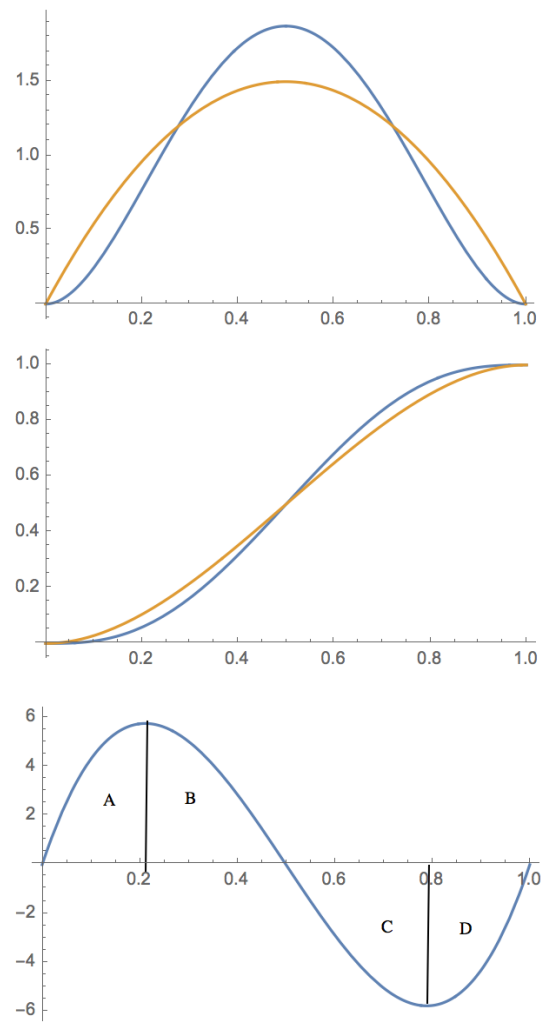

Figure 2.1: Double crossing density functions, single crossing CDFs and $F_{\alpha}(I, \alpha)$ function

effect on the CDF as in equation (2.2) below. These summarized properties of the mean preserving income distribution are crucial to my market demand analysis in later sections.

$$
\left\{\begin{array}{llll}
f_{\alpha}(I, \alpha) \geq 0 & \& & F_{\alpha}(I, \alpha)>0 & \text { if } I \in\left[I_{\text {min }}, I_{A}\right] \\
f_{\alpha}(I, \alpha)<0 & \& & F_{\alpha}(I, \alpha) \geq 0 & \text { if } I \in\left[I_{A}, I_{B}\right] \\
f_{\alpha}(I, \alpha) \leq 0 & \& & F_{\alpha}(I, \alpha)<0 \geq 0 & \text { if } I \in\left[I_{B}, I_{C}\right] \\
f_{\alpha}(I, \alpha)>0 & \& & F_{\alpha}(I, \alpha) \leq 0 & \text { if } I \in\left[I_{C}, I_{\max }\right]
\end{array}\right.
$$

I assume that consumers make their purchase decisions based on their according reservation prices. The higher a consumer's income level the greater the consumer's reservation price for a consumption good. Doing so, I am able to identify mar- 
ket demand by mirroring consumers' income distributions to their corresponding reservation prices.

The assumption of strict proportionality of consumers reservation prices to their incomes seems dramatically uncomplicated, however, is suggested by Deaton and Muellauer (1980) and also applied in the literature (Anderson et al. 1992). Since my argument rests on the idea of a simple version of mean preserving spread on income levels, it is convenient to use the income-price assumption to analyze the relationship between consumers' income heterogeneity and market demand without great loss of generality while keeping the essential explaining power relevant to my research question.

I assume that each consumer purchases at most one unit of a product at a price less than or equal to his or her corresponding reservation price. The market demand for the product can then be established as follows:

$$
D(p, \alpha)=1-F(p, \alpha)
$$

Equation (2.3) shows that market demand $D(p, \alpha)$ is a function of the market price $p$ and the mean preserving parameter $\alpha$ of the income distribution $F(p, \alpha)$. Clearly, changes in the mean preserving parameter $\alpha$ can determine the status of market demand at a given price level. And due to my specific assumptions of the income distribution, changes in the mean preserving parameter $\alpha$ affect market demand differently depending on the position of the price level relative to the corresponding income level in the intervals for a given income distribution.

I assume that the representative consumer's utility function is of a non-homothetic form so that the expenditure function and demand function allow for a concave or convex shape instead of a linear shape. Such specific setting allows the mean preserving parameter $\alpha$ to affect the expenditure function and in turn market demand. 
Doing so I am able to establish an important relationship that is the immediate connection between income distributions and market demand.

To sum up, in this section I establish the mean preserving income distribution as the desired income distribution center to my investigation since my goal is to study how distributive changes in income distribution affect firms' decision-making on international expansions: foreign direct investment (FDI) and export. I investigate how changes in the mean preserve parameter $\alpha$ translate into movements of these firms' decision-making. A decrease in the mean preserving parameter $\alpha$ represents a less concentrated income level around the average income, whereas an increase in the mean preserving parameter $\alpha$ indicates a more dispersed income distribution for a given income distribution. How does a situation like this affect market demand and hence a firms' profitability in otherwise identical market conditions? The key to answering this question is to understand the impact of a shift in the mean preserve parameter $\alpha$ on market demand and profitability of these internationally engaged firms under different circumstances.

\subsection{International expansion}

For illustration purposes, I consider a single representative firm who currently sells only in the home country but considers expand its business overseas. The firm faces two mutually exclusive options for the international expansion: horizontal foreign direct investment (FDI) and export. To engage in FDI, the firm needs to invest in chosen foreign countries to establish associated foreign affiliates in order to produce and serve these foreign markets. To adopt the export strategy, the firm exports its domestically manufactured products to foreign markets while incurring trade costs. ${ }^{4}$

\footnotetext{
${ }^{4}$ I only consider the transport cost, which takes the form of the iceberg trade cost.
} 
To become a multinational entity, the representative firm invests $K$ amount of capital to build a plant in the host country. The investment is fixed, and once invested it becomes sunk and unrecoverable. However, the firm needs to pay iceberg type per unit trade costs (denoted as $t>1$ ) to ship domestic goods to foreign destinations to become an exporter. In addition to the two different types of fixed costs, the firm pays a constant unit production cost $c$ regardless of the adoption of either international business strategy.

I denote the representative firm's profits under FDI and export strategies as $\Pi_{f}$ and $\Pi_{e}$, respectively. The firm maximizes its corresponding profits according to the following two separate profit functions:

$$
\left\{\begin{array}{l}
\Pi_{f}=p_{f} D_{f}\left(p_{f}, \alpha\right)-c D_{f}\left(p_{f}, \alpha\right)-K \\
\Pi_{e}=p_{e} D_{e}\left(p_{e}, \alpha\right)-c D_{e}\left(p_{e}, \alpha\right)-t D_{e}\left(p_{e}, \alpha\right)
\end{array}\right.
$$

I obtain the two equilibrium prices by solving for the optimized prices as shown in equation (2.5) and equation (2.6) below:

$$
\begin{gathered}
p_{f}=\frac{1-F\left(p_{f}, \alpha\right)-c f\left(p_{f}, \alpha\right)}{f\left(p_{f}, \alpha\right)} \\
p_{e}=\frac{1-F\left(p_{e}, \alpha\right)-(c-t) f\left(p_{e}, \alpha\right)}{f\left(p_{e}, \alpha\right)}
\end{gathered}
$$

In order to make proper decisions on which strategy to adopt, the firm compares the two profits earned in the two alternative scenarios. If profits earned under FDI strategy is greater than profits earned under export strategy, the firm chooses a FDI strategy over export, and vice versa. Mathematically, the condition can be written as $\Delta \Pi=\Pi_{f}-\Pi_{e}>0$, which yields three different case scenarios for the firm. I analyze the three different cases in details in the following sections. 


\subsubsection{Case I: $p_{f}=p_{e}$}

Firstly, I analyze the case in which the representative firm sets prices under the two alternative strategies equal to each other in the host country: $p_{f}=p_{e}$. The associated profits differential function can be simplified down to the expression $t D(p, \alpha)-K$, where $t D(p, \alpha)$ is the trade cost under the export strategy and $K$ is the fixed cost under the FDI strategy.

The firm chooses the FDI strategy over the export strategy if $t D(p, \alpha)-K>0$ or $t D(p, \alpha)>K$. Likewise, it chooses the export strategy over the FDI strategy if $t D(p, \alpha)-K<0$ or $t D(p, \alpha)<K$. The firm chooses to adopt an FDI strategy if trade costs associated with exporting are higher than the amounts required to build a plant in the host country, and vice versa.

Suppose now that the host country encounters a distributive shock to its consumers' income, ${ }^{5}$ the shape of the corresponding income distribution changes as a result. To show how the distributive shock affects market demand and in turn the firm's profitability, I first take a partial derivative with respect to the mean preserving parameter $\alpha$ to the profits differential function $\Delta \Pi$ to obtain the following result:

$$
\Delta \Pi_{\alpha}=\frac{\partial \Delta \Pi}{\partial \alpha}=-c F_{\alpha}(p, \alpha)
$$

Equation (2.7) shows clearly that the impact depends on the price and the position of the mean preserving parameter $\alpha$ in the intervals of the income distribution. For instance, if the firm sets the price in combined region $A+B$ so $p \in\left(I_{\text {min }}, I_{B}\right)$ market demand increases in this region as the mean preserving parameter $\alpha$ increases, and I obtain the associated change in market demand $F_{\alpha}>0$. The following result of the profit differential function ensues: $\Delta \Pi_{\alpha}<0$.

\footnotetext{
${ }^{5}$ This can be represented by a decrease or an increase in the mean preserving parameter $\alpha$ of the income distribution.
} 
Suppose that currently the firm adopts an FDI strategy so that the profit function is $\Pi_{f}>\Pi_{e}$. The calculated result calculated means that the difference between two profits earned under the two alternative strategies becomes larger. The firm chooses to stay in the foreign market as a multinational enterprise when the income distribution becomes more concentrated around the mean. ${ }^{6}$ This shift in income in region $A+B$ comes from the joining middle income group by the the previously lowincome population. If, on the other hand, the firm was under the export strategy the firm has an incentive to switch from the export strategy to adopting the alternative FDI strategy when the gap between two profits $\Pi_{f}$ and $\Pi_{e}$ is greater than zero and continues to grow sufficiently large.

For region $C+D$ as shown in Figure 2.1 the profit differential function $\Delta \Pi_{\alpha}>$ 0 when $p \in\left(I_{b}, I_{\max }\right)$ because market demand is negatively related to the mean preserving parameter $\alpha$ so the associated change in market demand $F_{\alpha}<0$. In this case, the originally positive gap between two profits under the two alternative strategies closes as the income shifts towards the mean value from both tails. ${ }^{7}$ I assume that the firm has a multinational status, such change in income distribution entices the firm to quit being a multinational and switch to an export strategy once the the gap closes completely and turns negative.

When $p_{f}=p_{e}$ and $\Delta \Pi>0 \mathrm{I}$ am able to obtain the following results: as a country becomes more equal in its consumers' income levels, i) the representative firm who initially adopts an FDI strategy remains a multinational enterprise when the original price is in the lower half of reservation price interval in Figure 2.1; ii) the firm that adopts an FDI strategy may switch to an export strategy when the

\footnotetext{
${ }^{6}$ It means that there are more middle class people in the economy, holding everything else constant.

${ }^{7}$ Although the source of the distributive change comes from both ends, the focus is region $C+D$ or the decrease in income of high-income consumers from the right end.
} 
predate price is greater than $I_{B}$ as shown in Figure 2.1 and the decrease in the profits difference between FDI profits and export profits is sufficiently large.

I then move on to show the three cases in which prices under the two strategies are different from each other, and the three cases are: case i) $p_{f} \neq p_{e}: p_{f}$ with $p_{e}$ in the same interval; case ii) $p_{f}>p_{e}$ with $p_{f}$ and $p_{e}$ in different intervals; and case iii) $p_{f}<p_{e}$ with $p_{f}$ and $p_{e}$ in different intervals.

In all three cases I use the same profit difference equation $\Delta \Pi$, which is derived as $\Delta \Pi=\left(p_{f} D\left(p_{f}, \alpha\right)-K\right)-\left(\left(p_{e}-c-t\right) D\left(p_{e}, \alpha\right)\right)$. Clearly, change in the profit difference depends on the mean preserving parameter and a change in the mean preserving parameter $\alpha$ is associated with changes in both market demand and the price. To reduce the complexity of calculation without losing the essential explaining power, I assume fixed prices but flexible market demand. ${ }^{8}$ Taking a partial derivative with respect to the mean preserving parameter $\alpha$ I acquire the following equation:

$$
\frac{\partial \Delta \Pi}{\partial \alpha}=p_{f} \frac{\partial D_{f}}{\partial \alpha}-\left(p_{e}-c-t\right) \frac{\partial D_{e}}{\partial \alpha}
$$

where $\Delta \Pi=\Pi_{f}-\Pi_{e}$ and is the profit differential function. The change in the profit differences under the two strategies depends on the change in the associated market demand while holding prices constant.

\subsubsection{Case II: $p_{f} \neq p_{e}$ and $p$ in the same interval}

i) $p \in\left(I_{\min }, I_{B}\right)$.

For $p \in\left(I_{\text {min }}, I_{B}\right)$, I have $p_{f} \frac{\partial D_{f}}{\partial \alpha}<0$ and $\left(p_{e}-c-t\right) \frac{\partial D_{e}}{\partial \alpha}<0$. I investigate the effect of a more concentrated income due to a decrease in the mean preserving parameter $\alpha$ on market demand $F(p, \alpha)$. As income becomes more concentrated around the mean value of the income distribution, market demand in interval $p \in$

\footnotetext{
${ }^{8}$ This is a short-term assumption as firms do not revise prices frequently in short-term.
} 
$\left(I_{\text {min }}, I_{B}\right)$ falls as prices stay fixed according to my assumption. Again, I assume that the firm is under a FDI strategy because $\Delta \Pi=\Pi_{f}-\Pi_{e}>0$.

The partial derivative of the profit differential with respect to the mean preserving parameter $\alpha$ is $\frac{\partial \Delta \Pi}{\partial \alpha}<0$ because the increase in revenues under the FDI strategy associated with a rise in market demand outweighs gains in profits under the export strategy following the increase in market demand. This result means that a negative distributive shock $(\alpha<0)$ to income does not affect the firm's initial decision on the international expansion as the positive gap between the two profits widens. On the other hand, a reverse case happens when the partial derivative of the profit differential with respect to the mean preserving parameter $\alpha$ is $\frac{\partial \Delta \Pi}{\partial \alpha}>0$. Under this circumstance, a more concentrated income around its mean narrows the gap between two profits under the two alternative strategies. The firm has an incentive to switch from the FDI strategy to the export strategy once the gap closes completely and turns negative.

ii) $p \in\left(I_{B}, I_{\max }\right)$.

If the price $p$ is set in between $I_{B}$ and $I_{\text {max }}$ by the firm, I have $p_{f} \frac{\partial D_{f}}{\partial \alpha}>0$ and $\left(p_{e}-c-t\right) \frac{\partial D_{e}}{\partial \alpha}>0$. Again I assume that the firm adopts the FDI strategy to begin with. There are two sub-cases to consider in this scenario. The first one is $p_{f} \frac{\partial D_{f}}{\partial \alpha}<\left(p_{e}-c-t\right) \frac{\partial D_{e}}{\partial \alpha}$, and in this case I obtain a result $\frac{\partial \Delta \Pi}{\partial \alpha}<0$. Giving the price and income intervals, the shift in consumers' income levels towards the middle of the income distribution within this interval is accompanied by a decrease in market demand hence a fall in the firm's revenues under the FDI strategy. If the decrease in revenues under the FDI strategy is smaller than the decline of the projected profits under the alternative export strategy, the gap between two profits gets bigger. The firm has an incentive to continue the FDI strategy as a multinational entity in the targeted foreign market. The second one is the reverse case in which $p_{f} \frac{\partial D_{f}}{\partial \alpha}>$ 
$\left(p_{e}-c-t\right) \frac{\partial D_{e}}{\partial \alpha}$. I obtain a result $\frac{\partial \Delta \Pi}{\partial \alpha}>0$. The firm has an incentive to stay in the host country as a multinational.

\subsubsection{Case III: $p_{f} \neq p_{e}$ and $p$ in different intervals}

Again, I assume that the representative firm adopts an FDI strategy to begin with. The sign of the profit differential function $\Delta \Pi$ becomes immediately clear if $p_{f} \neq p_{e}$ and $p_{f}$ and $p_{e}$ are in different intervals of the income distribution. I consider the following two sub-cases:

i) $p_{f}>p_{e}, p_{f} \in\left(I_{B}, I_{\max }\right)$ and $p_{e} \in\left(I_{\min }, I_{B}\right)$.

For $p_{f} \in\left(I_{B}, I_{\max }\right)$ and $p_{e} \in\left(I_{\min }, I_{B}\right)$ I have $\frac{\partial D_{p_{f}, \alpha}}{\partial \alpha}>0$ and $\frac{\partial D_{p_{e}, \alpha}}{\partial \alpha}<0$, respectively. Therefore, I am able to obtain the following result $\frac{\partial \Delta \Pi}{\alpha}=p_{f} \frac{\partial D_{p_{f}, \alpha}}{\partial \alpha}-$ $p_{e} \frac{\partial D_{p_{e}, \alpha}}{\partial \alpha}>0$ or in short just $\frac{\partial \Delta \Pi}{\alpha}>0$.

The rise of the middle income class due to the decrease in the mean preserving parameter $\alpha$ put a threat on the representative firm's revenues generating capability because of the fall in market demand in the income interval of $I \in\left(I_{B}, I_{\max }\right)$ as shown in Figure 2.1. The projected earnings under an export strategy on the other hand increase in the same situation. The reverse in the revenue generating mechanism results in a possible switch from an FDI strategy to an export strategy eventually.

ii) $p_{f}<p_{e}, p_{e} \in\left(I_{B}, I_{\max }\right)$ and $p_{f} \in\left(I_{\min }, I_{B}\right)$.

For $p_{e} \in\left(I_{B}, I_{\text {max }}\right)$ and $p_{f} \in\left(I_{\text {min }}, I_{B}\right)$ I have $\frac{\partial D_{p_{e}, \alpha}}{\partial \alpha}>0$ and $\frac{\partial D_{p_{f}, \alpha}}{\partial \alpha}<0$, respectively. Therefore, I obtain the following result for the $\Delta \Pi$ function: $\frac{\partial \Delta \Pi}{\alpha}=$ $p_{f} \frac{\partial D_{p_{f}, \alpha}}{\partial \alpha}-p_{e} \frac{\partial D_{p_{e}, \alpha}}{\partial \alpha}<0$ or in short $\frac{\partial \Delta \Pi}{\alpha}<0$.

By setting the price lower than $p_{e}$ in interval $I \in\left(I_{m i n}, I_{B}\right)$ of the income distribution, the representative firm is able to continue the FDI strategy as a multinational 


\begin{tabular}{|c|c|c|}
\hline Cases \& Intervals & Change in demand & Sign \& change in $\Delta \Pi$ \\
\hline \multicolumn{3}{|l|}{$p_{f}=p_{e}$} \\
\hline$p \in A$ & $\frac{\partial D(p, \alpha)}{\partial \alpha}<0$ & $-\& \Delta$ profit $\uparrow$ \\
\hline$p \in B$ & $\frac{\partial D(p, \alpha)}{\partial \alpha}>0$ & $+\& \Delta$ profit $\downarrow$ \\
\hline \multicolumn{3}{|l|}{$p_{f} \neq p_{e}$} \\
\hline$p_{f} \& p_{e} \in A$ & $\frac{\partial D(p, \alpha)}{\partial \alpha}<0$ & $\begin{array}{l}- \text { for } \Delta R<\Delta \Pi, \& \Delta \text { profit } \uparrow \\
+ \text { for } \Delta R>\Delta \Pi, \& \Delta \text { profit } \downarrow\end{array}$ \\
\hline$p_{f} \& p_{e} \in B$ & $\frac{\partial D(p, \alpha)}{\partial \alpha}>0$ & $\begin{array}{l}- \text { for } \Delta R<\Delta \Pi, \& \Delta \text { profit } \uparrow \\
+ \text { for } \Delta R>\Delta \Pi, \& \Delta \text { profit } \downarrow\end{array}$ \\
\hline \multicolumn{3}{|l|}{$p_{f}>p_{e}$} \\
\hline$p_{f} \in B \& p_{e} \in A$ & $\frac{\partial D(p, \alpha)}{\partial \alpha}>0 \& \frac{\partial D(p, \alpha)}{\partial \alpha}<0$ & $\frac{\partial \Delta \Pi}{\partial \alpha}>0, \& \Delta$ profit $\downarrow$ \\
\hline \multicolumn{3}{|l|}{$p_{f}<p_{e}$} \\
\hline$p_{f} \in A \& p_{e} \in B$ & $\frac{\partial D(p, \alpha)}{\partial \alpha}<0 \& \frac{\partial D(p, \alpha)}{\partial \alpha}>0$ & $\frac{\partial \Delta \Pi}{\partial \alpha}<0, \& \Delta$ profit $\uparrow$ \\
\hline
\end{tabular}

Table 2.1: Summary of all cases

enterprise as a shift to the more concentrated middle income status occurs. The positive distributive shock in consumers' income levels boosts market demand for the firm's product in this interval whereas it reduces the market share for a price that is in interval $I \in\left(I_{B}, I_{\max }\right)$. The overall effect of the distributive shock can be shown as $\frac{\partial \Delta \Pi}{\alpha}<0$ and is negative. The firm has an incentive to remain as a multinational firm under the FDI strategy in the host country.

Overall, I find that a more equal distribution in income such as a concentration on middle income contributes to creating a more competitive market for firms hence affecting the decision-making regarding international expansion by these firms.

I summarize my findings for $p_{f}=p_{e}$ and for all cases $p_{f} \neq p_{e}$ in this section in Table 2.1 . 


\subsection{Empirical Model}

\subsection{Data description}

The empirical part of my study is confined to bilateral trade relationships between the U.S. and the rest of the world by mainly utilizing the 2002 - 2013 U.S. Bureau of Economic Analysis (BEA) panel FDI and trade data disaggregated by industry and country. The BEA data covers bilateral U.S. activities in foreign direct investments (FDI) and international trade, and is the most complete set of data disaggregated by industry. Data on bilateral trade and FDI between the U.S. and the rest of the world are disaggregated and classified at the three-digit industry level by the North American Industry Classification System (NAICS) standard.

Due to the non-tradability of services and the limitation in data availability of trade costs (tariffs, transport costs, etc.), service industries including finance, wholesale, retail and utilities are excluded in my data selection. Moreover, since my analysis focuses on trade of final goods, primary industry is also not included in my data selection.

My selected sample contains data for nine countries: Canada, France, Germany, United Kingdom, Australia, Japan, Brazil, Mexico and China. Six of the nine countries are developed countries, which have relatively low income inequality proxied by the Gini coefficients. The rest of the three countries are developing countries with relatively high income inequality or high Gini coefficients relative to more advanced countries. ${ }^{9}$ The reason behind the differences in Gini coefficients between the two groups of countries is not within the scope of this study. However, the idiosyncratic characteristics that are particular to each country and influence the regressors under

\footnotetext{
${ }^{9}$ Six developed countries are Canada, France, Germany, United Kingdom, Australia, and Japan. And three developing countries are Brazil, Mexico and China.
} 
the empirical study may bias the estimation results. Therefore, I try to eliminate such bias by controlling for the effect of those time-invariant characteristics in order to better assess the net effect of Gini coefficients on the outcome variables.

The fixed effects in my model are assumed to only vary across countries but not over time. Moreover, since my data span 12 years of period from 2002 to 2013, special events that affect the outcome variables may happen within a country, I also control for these unexpected events by removing the time effects.

In the theoretical model, the change of the income distribution stems from a shift of the mean-preserving parameter $\alpha$, which is proxied by the Gini coefficient in the empirical study. The behavior of export, FDI, and the export to FDI ratio or export-FDI ratio in relation to the Gini coefficients variable is of particular interest to me. Each predicted value is the conditional mean or the expected value with respect to the corresponding Gini coefficient. It tells me how the average value of export, FDI and exp-FDI ratio are related to each value of the Gini coefficient.

Figure 2.2 displays the scatterplots between FDI affiliate sales, exp-FDI ratio and Gini coefficients. For the scatterplot of the export-FDI ratio and Gini coefficients, a downward trend between the two variables is observed suggesting a possible negative correlation between the export-FDI ratio and Gini coefficients. However, the correlation between FDI affiliate sales and Gini coefficients is not obvious in the graph.

\subsubsection{Model specification}

In the FDI and trade literature, factors such as trade costs, ${ }^{10}$ exchange rates, taxes, production factors of the host country, proprietary rights and other unobserved factors may also affect firms' decision-making on their international expansion. More-

\footnotetext{
${ }^{10}$ Transport costs and all types of trade barriers.
} 

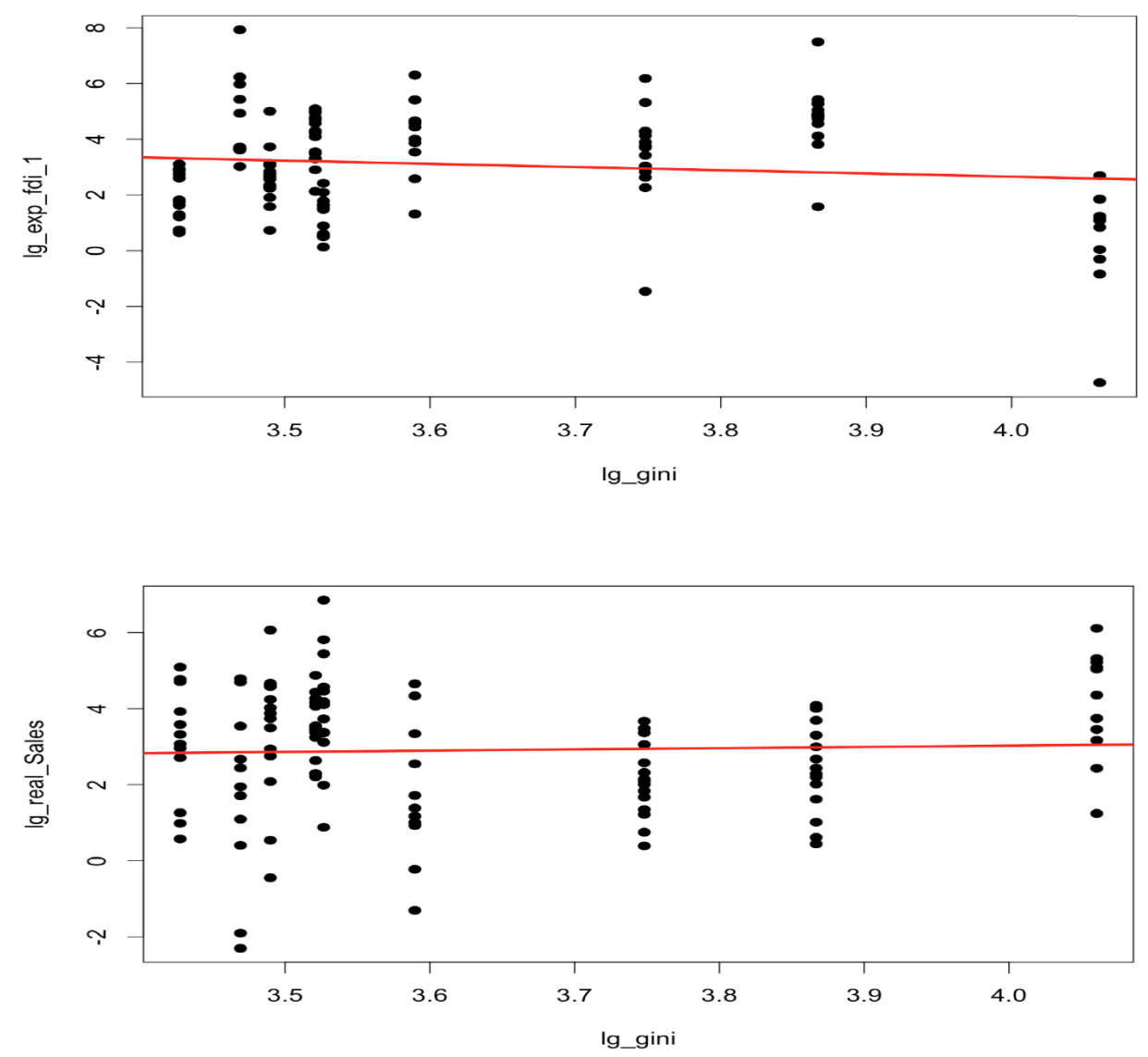

Figure 2.2: Scatterplots: i) export-FDI ratio and Gini coefficients (up), ii) FDI affiliate sales and Gini coefficients (down)

over, some intrinsic randomness in the exports and FDI sales is bound to occur that cannot be explained because of human behavior. In addition to the randomness, the stochastic term may also be an indication of errors of measurement.

I am not able to control for heterogeneity at a firm level due to the data limitation. By definition, heterogeneity is the unobserved variable that does not change over time. The business practices of a company influence its operations in certain destinations. Alternatively, I investigate firm heterogeneity across countries prevalent in different entities. A regular OLS regression method does not take into account heterogeneity across groups or time. 
I justify the econometric model by referring to developed theories in the trade and FDI literature. Stochastic factors that may represent other influential independent variables to dependent variable are explicitly included in the model. Other factors might affect the dependent variable, yet their combined effects on the dependent variable may be nonsystematic so they can be incorporated in the error term.

A seemingly natural factor that affects firms' decisions on international expansions is trade protection. The trade protection hypothesis states that such protection makes firms likely to substitute FDI production in host countries for exports. Belderbos (1997) and Blonigen (2002) find evidence of tariff-jumping FDI by using antidumping measures as the form of trade protection. Although trade protection has forms of both non-tariff and tariff, in my study I only use tariffs to proxy trade protection.

Firms with intangible assets such as managerial skills and technologies specific to them intend to do business in foreign markets are likely to become multinational enterprises (MNEs) to internalize market transactions on their own. Conventionally, R\&D intensity and advertising intensity are used as proxies for intangible assets. In my investigation I establish the R\&D intensity and use it as the proxy for intangible assets. The R\&D intensity indicator is constructed by using business and industrial R\&D data collected from the National Science Foundation website.

Depreciation and/or appreciation of currencies in use also affect firms' decisionmaking on their international expansions. Swenson (1994) and Kogut and Chang (1996) find evidence that short-run movements in exchange rates lead to increased inward FDI. Desai et al (2004a) find that the U.S. foreign affiliates increase their investment significantly more than local firms during and subsequent to a currency crisis. 
Effects of taxes on FDI and cross-border trade have been investigated heavily both theoretically and empirically. According to the hypothesis higher taxes are supposed to discourage FDI. De Mooij and Ederveen (2003) discover a median taxelasticity of FDI of -3.3 across 25 studies.

The trade literature also shows that the quality of institutions has non-trivial impacts on FDI activities. Poor quality of institutions of a host country increases the cost of doing business in the foreign market and should therefore negatively affect FDI activities. Due to difficulties in measuring the quality of institutions across countries, certain indices such as a corruption index is used as the proxy for the quality of institution. Wei (2000a, b) shows that corruption negatively affects FDI activities. In this study I obtain the corruption index from the Transparency Agency website. This corruption index can be interpreted as follows: the higher the corruption index, the less corrupted a country's public sector.

I first construct the base model using OLS, taking into account all fixed effects and estimate the impact of the change in the income distribution by establishing the following econometric model:

$$
\begin{aligned}
\text { ExFDI }_{i}= & b_{0}+b_{1} \text { Gini }_{i}+b_{2} \text { ExRate }_{i}+b_{3} \text { Tariff }_{i}+b_{4} \text { GDP }_{i}+b_{5} \text { Assets }_{i}+ \\
& +b_{6} \text { Compen }_{i}+b_{7} \text { Corrup }_{i}+b_{8} \text { CorpTax }_{i}+ \\
& +b_{9} \text { R\&D }_{i}+b_{10} \text { RelExp }_{i}+b_{11} \text { ExpAf }_{i}+ \\
& + \text { Trend }+ \text { FixedEffects }+u_{i}
\end{aligned}
$$

where Gini $_{i}$ variable is the Gini coefficient obtained from the World Bank database; ExRate $_{i}$ is the nominal exchange rates acquired from the Federal Reserve Bank at St. Louis database; Tarif $f_{i}$ is the disaggregated industry level customs tariff retrieved from the World Trade Organization (WTO) database; $G D P_{i}$ is the real GDP; Assets $_{i}$ is the Producers Purchase Index (PPI) deflated real capital stock; Compen $_{i}$ is the FDI compensation paid to its affiliates and a firm size proxy; Corrup 
is the corruption index created by the Transparency Agency; corpTax $i$ is the yearly corporate tax collected by KPMG; $R \& D_{i}$ is the calculated R\&D intensity; RelExp is the real exports; $\operatorname{Exp} A f_{i}$ is the real exports shipped to FDI affiliates and a proxy for intermediate inputs; Trend is the trend variable accounting for fixed time effects; FixedEffects accounts for fixed effects of choices; and $u_{i}$ is the disturbance term.

Equation (2.9) is a log-linear function, so all slope coefficients are partial elasticities of the dependent variable with respect to the appropriate explanatory variable.

\subsubsection{Results}

I report OLS estimates results with and without fixed effects for comparison. I also re-estimate the base model with a modified least-square fixed effects method and compare the results with OLS estimates without fixed effects.

My model suggests that FDI itself has trade effects. Exports are associated with higher variable costs of trade barriers and transport costs, whereas FDI affiliate sales involve high fixed costs relative to exports. Therefore, firms have an incentive to substitute one strategy for the other depending on the differentials in such costs. For example, a natural switch from exports to FDI in a foreign country occurs once the market is sufficiently large hence has scale economy for MNEs products to overcome the high fixed sunk costs. Trade effects suggest a negative relationship between exports and FDI affiliate sales controlling for intermediate exports. Blonigen (2001) and Head and Ries (2001) find evidence by using Japanese firm-level data that increase in outbound FDI in the U.S. is negatively related to Japanese exports of the same finished products.

Table 2.2 presents the estimated results of the base model suggested by equation (2.9). Although not reported in Table 2.2, I include both fixed industry effects 


\begin{tabular}{|c|c|c|c|c|}
\hline \multirow{4}{*}{$\begin{array}{c}\text { Independent Variable } \\
\text { Trend }\end{array}$} & \multicolumn{4}{|c|}{ Dependent Variable } \\
\hline & \multicolumn{2}{|c|}{ Export-FDI ratio } & \multicolumn{2}{|c|}{ FDI affiliate sales } \\
\hline & $0.02914 * *$ & -0.0136 & $0.0070^{*}$ & $0.0094 * *$ \\
\hline & $(0.0144)$ & $(0.0091)$ & $(0.0037)$ & $(0.0044)$ \\
\hline \multirow{2}{*}{ Constant } & $-11.1651 * * *$ & 0.4398 & 0.7176 & $2.5303 * *$ \\
\hline & $(2.0717)$ & $(2.1770)$ & $(0.5682)$ & $(1.1675)$ \\
\hline \multirow{2}{*}{$\log$ of Gini } & $2.2593 * * *$ & $-1.1367 * * *$ & 0.1684 & -0.0673 \\
\hline & $(0.4379)$ & $(0.3003)$ & $(0.1132)$ & $(0.1564)$ \\
\hline \multirow{2}{*}{ log exchange rate } & $0.3056 * * *$ & -0.01642 & $0.0534 * * *$ & $0.4456^{* * *}$ \\
\hline & $(0.0357)$ & $(0.0231)$ & $(0.0092)$ & $(0.01085)$ \\
\hline \multirow{2}{*}{$\log$ tariff WA } & $-1.0278 * * *$ & $0.1464 *$ & 0.0463 & $0.0673^{*}$ \\
\hline & $(0.1468)$ & $(0.0844)$ & $(0.0380)$ & $(0.0373)$ \\
\hline \multirow{2}{*}{$\log$ of gdp } & $0.4402 * * *$ & $0.3123 * * *$ & $-0.0558 *$ & $-0.0906 * * *$ \\
\hline & $(0.1154)$ & $(0.0654)$ & $(0.0298)$ & $(0.0313)$ \\
\hline \multirow{2}{*}{ Total assets } & $-0.5967 * * *$ & $-0.4413 * * *$ & $0.5650 * * *$ & $0.5285^{* * *}$ \\
\hline & $(0.0911)$ & $(0.0478)$ & $(0.0236)$ & $(0.0258)$ \\
\hline \multirow{2}{*}{ FDI Compensation } & 0.0704 & $-0.5231 * * *$ & $0.4746 * * *$ & $0.4689 * * *$ \\
\hline & $(0.1004)$ & $(0.0544)$ & $(0.0260)$ & $(0.0311)$ \\
\hline \multirow{2}{*}{ Corruption Index } & & $-0.3953 * * *$ & & -0.0068 \\
\hline & & $(0.1519)$ & & $(0.0758)$ \\
\hline \multirow{2}{*}{ Corporate Income Tax } & & $-0.7137 * * *$ & & -0.0424 \\
\hline & & $(0.2719)$ & & $(0.1268)$ \\
\hline \multirow{2}{*}{ R\&D Intensity } & & $-4.0567 * *$ & & 0.4652 \\
\hline & & $(1.9459)$ & & $(0.8649)$ \\
\hline \multirow{2}{*}{ Related Exports } & & $0.6974 * * *$ & & \\
\hline & & $(0.0176)$ & & \\
\hline \multirow[t]{2}{*}{ Exports to Affiliates } & & & & $0.0320 * * *$ \\
\hline & & & & $(0.0017)$ \\
\hline Industry fixed effects & No & Yes & No & Yes \\
\hline Adjust R squared & 0.5813 & 0.8981 & 0.9723 & 0.9746 \\
\hline F statistic & 148.7471 & 518.3354 & 3738.3 & 1679.05 \\
\hline Numerator d.f. & 7 & 12 & 7 & 12 \\
\hline Denominator d.f. & 738 & 692 & 738 & 512 \\
\hline \# of Obs & 746 & 705 & 746 & 515 \\
\hline
\end{tabular}

Notes: i) All variables are in log values except for Exp_FDI ratios.

ii) Numbers reported in parentheses are standard errors.

iii) Significance codes: $* 10 \%, * * 5 \%, * * * 1 \%$.

iv) Related exports is trade with an entity located outside the United States in which the exporter holds at least a $10 \%$ equity.

Table 2.2: OLS estimates 
and country effects in estimation since it is possible that the errors are correlated across different industries and countries. The first two columns report OLS estimates of equation (2.9) using export-FDI ratio as the dependent variable including results with and without industry fixed effects. Columns (iv) - (vii) reports the OLS estimate of equation (2.9) using FDI affiliate sales and affiliates net income as dependent variables with and without industry fixed effects, respectively.

The coefficients on Gini coefficients, the exchange rate, real GDP, real total assets, corruption index, and R\&D intensity have the predicted signs and are statistically significant except for the exchange rate. The coefficients on tariffs and corporate income tax diverge from the predicted sign.

Though not statistically significant, my finding of the negative sign of the partial effect of exchange rates on the sales to U.S. foreign affiliates is in accordance with the suggestions by literature. The partial coefficient for R\&D intensity is -4.0567 , indicating that a one percentage increase in the R\&D intensity lead to a four percentage decrease in the exports-FDI ratio, which is consistent with past findings that R\&D intensity is positively related to FDI sales.

The coefficient on Gini coefficients on export-FDI ratio is negative and statistically significant, indicating that exports are smaller relative to FDI affiliate sales the greater the Gini coefficients. A relatively high Gini coefficient represents a more unequal condition in income distribution. This result suggests that a more concentrated income distribution as shown in the theoretical model is associated with relatively low export to FDI ratio than a more dispersed income distribution. The corruption index has negative influence on the export-FDI ratio. As a country becomes more politically stable as measured by a higher corruption index, foreign firms have incentives to invest in the country and become MNEs. 


\begin{tabular}{|c|c|c|c|c|c|c|}
\hline \multirow{3}{*}{$\begin{array}{c}\text { Independent } \\
\text { Variable }\end{array}$} & \multicolumn{6}{|c|}{ Dependent Variable } \\
\hline & \multicolumn{6}{|c|}{ Ex-FDI ratio } \\
\hline & \multicolumn{2}{|c|}{ OLS } & & \multicolumn{3}{|c|}{ LSFE } \\
\hline $\log$ of Gini & $\begin{array}{l}-1.1490 \\
(0.9048)\end{array}$ & $\begin{array}{c}10.2093 * * * \\
(1.9000)\end{array}$ & $\begin{array}{l}8.6780^{* *} \\
(3.5900)\end{array}$ & $\begin{array}{l}1.1668^{* * * *} \\
(0.1091)\end{array}$ & $\begin{array}{l}7.0172 * * * \\
(1.4121)\end{array}$ & $\begin{array}{c}3.0441^{* * *} \\
(1.1120)\end{array}$ \\
\hline log exchange rate & & $\begin{array}{l}-0.1844 \\
(0.2010)\end{array}$ & $\begin{array}{c}0.8719 \\
(1.0470)\end{array}$ & & $\begin{array}{l}-0.4534^{*} \\
(0.2416)\end{array}$ & $\begin{array}{l}-0.1609 \\
(0.5421)\end{array}$ \\
\hline log tariff WA & & $\begin{array}{c}-0.2203^{*} \\
(0.1168)\end{array}$ & $\begin{array}{l}-0.0303 \\
(0.0927)\end{array}$ & & $\begin{array}{c}-0.2431^{* *} \\
(0.1127)\end{array}$ & $\begin{array}{l}-0.0303 \\
(0.0927)\end{array}$ \\
\hline $\log$ of gdp & & $\begin{array}{l}0.9742 * * * \\
(0.3123)\end{array}$ & $\begin{array}{l}1.4470 * * \\
(0.6345)\end{array}$ & & $\begin{array}{c}-1.2412 * * * \\
(0.3361)\end{array}$ & $\begin{array}{c}0.1218 \\
(0.2886)\end{array}$ \\
\hline Total assets & & $\begin{array}{c}-0.3478 * * * \\
(0.0678)\end{array}$ & $\begin{array}{c}-0.5963 * * * \\
(0.0976)\end{array}$ & & $\begin{array}{c}-0.3469 * * * \\
(0.0653)\end{array}$ & $\begin{array}{c}-0.5963 * * * \\
(0.0976)\end{array}$ \\
\hline Openness to trade & & $\begin{array}{c}0.5577 \\
(0.9696)\end{array}$ & $\begin{array}{l}-1.7790 \\
(1.4210)\end{array}$ & & $\begin{array}{l}-0.4188 \\
(1.3771)\end{array}$ & $\begin{array}{c}0.5628 \\
(0.7916)\end{array}$ \\
\hline Openness to FDI & & $\begin{array}{c}-0.7728 * * * \\
(0.2468)\end{array}$ & $\begin{array}{c}1.9400 \\
(1.9790)\end{array}$ & & $\begin{array}{c}-1.3001 * * * \\
(0.4567)\end{array}$ & $\begin{array}{l}-0.5778 \\
(0.6957)\end{array}$ \\
\hline Corruption Index & & & $\begin{array}{c}5.4540 \\
(5.0920)\end{array}$ & & & $\begin{array}{l}-0.4307 \\
(1.8947)\end{array}$ \\
\hline $\begin{array}{c}\text { Corporate Income } \\
\text { Tax }\end{array}$ & & & $\begin{array}{l}1.7590 \\
(2.5960)\end{array}$ & & & $\begin{array}{c}-2.5985^{* * *} \\
(0.9471)\end{array}$ \\
\hline R\&D Intensity & & & $\begin{array}{l}-0.1703 \\
(0.1611)\end{array}$ & & & $\begin{array}{l}-0.1703 \\
(0.1611)\end{array}$ \\
\hline Related Exports & & & $\begin{array}{c}-0.4492 * * * \\
(-0.0719)\end{array}$ & & & $\begin{array}{c}0.4492 * * * \\
(0.0719)\end{array}$ \\
\hline Exports to Affiliates & & & $\begin{array}{l}-0.0001 \\
(0.0839)\end{array}$ & & & $\begin{array}{l}-0.0001 \\
(0.0839)\end{array}$ \\
\hline $\begin{array}{l}\text { Adjacent to the US } \\
\text { border }\end{array}$ & & & & & & $\begin{array}{c}0.2900 \\
(0.3416)\end{array}$ \\
\hline $\begin{array}{c}\text { Country fixed } \\
\text { effects }\end{array}$ & No & No & No & Yes & Yes & Yes \\
\hline $\begin{array}{l}\text { Country Random } \\
\text { effects }\end{array}$ & & & & No & No & No \\
\hline Adjust R squared & 0.0053 & 0.6327 & 0.8439 & 0.871 & 0.9336 & 0.9711 \\
\hline F statistic & 1.613 & 24.13 & 35.24 & 88.01 & 134.5 & 199.7 \\
\hline Numerator d.f. & 1 & 7 & 12 & 9 & 10 & 13 \\
\hline Denominator d.f. & 114 & 87 & 64 & 107 & 85 & 64 \\
\hline \# of Obs & 116 & 95 & 77 & 116 & 96 & 78 \\
\hline
\end{tabular}

Notes: i) All variables are in log values except for Exp_FDI ratios.

ii) Numbers reported in parentheses are standard errors.

iii) Significance codes: $* 10 \%, * * 5 \%, * * * 1 \%$.

iv) Related exports is trade with an entity located outside the United States in which the exporter holds at least a $10 \%$ equity.

Table 2.3: OLS and LSFE estimates 
Table 2.2 also shows that the destination-market affiliate total capital stock, compensation and industry R\&D intensity are important determinants of the presence of multinational activities than of the FDI share in the export-FDI ratio. Column (v) includes a full set of independent variables. The coefficients on Gini coefficients, the exchange rate, real GDP, real total assets, corruption index, the R\&D intensity and corporate income tax have the predicted signs and are statistically significant except for Gini coefficients. The negative sign of the Gini coefficients indicate the possibility of negative relationship between FDI affiliate sales and the change in income distribution.

In Table 2.3, I report both OLS estimates and LSFE (Least Square Fixed Effects) results for comparison. The difference between Table 2.3 and Table 2.2 is that I remove the Compensation variable and add Openness to Trade and Openness to FDI to the estimation. As Table 2.3 results show, the OLS results overestimate the effect of Gini coefficient on the outcome variable which is the export to FDI affiliate sales ratio. When fixed effects are taken into account, the effect of the exchange rate on the outcome variable changes sign from positive to negative. The effect of GDP becomes insignificant and is used to control for a country size. Per the LSFE estimates, the Openness to Trade is positive related to the export-FDI ratio whereas the Openness to FDI is negative related to the outcome variable and both are consistent with the trade and FDI literature as opposed to OLS results.

\subsection{Conclusion}

I investigate how distributive changes in income distribution affect firms' decisionmaking on international expansion: foreign direct investment (FDI) and export. I model the income distribution with a mean preserving income distribution with a 
continuous differentiable unimodal density function. I divide the density function and the partial derivative of the CDF into four intervals based on the effect of the mean preserving parameter on the income distribution. Changes in the mean preserving parameter in these intervals translate into movements of firms' decisionmaking on international expansions. I find that a more equal distribution in income such as a concentration on middle income contributes to creating a larger market hence a more competitive market for firms. In addition, some firms benefit from the increase in the market size. Using Gini coefficient as the proxy for income distribution, I develop an econometric model with fixed industry effects and country effects and demonstrate that some firms gain market shares and benefit from more consumers entering the middle class due to the corresponding change in income distribution. Moreover, the coefficients of the exchange rate, real GDP, real total assets, corruption index, and R\&D intensity have the predicted signs and are statistically significant. 


\section{CHAPTER 3 \\ INTRODUCTION}

Exports and foreign direct investment (FDI) are two main modes of delivering goods and services to overseas markets. In terms of growth rates, FDI sales have surpassed international trade since late 80's of last century and become the major way of international expansion for domestic firms.

I endogenize FDI and exports as two alternative strategies for international expansion for firms with heterogeneous productivity levels in a two-country world setting. I seek to understand responses of firms to changes in market environments such as time preferences by consumers and the impact of these exogenous changes on international trade.

I develop a dynamic, stochastic, general equilibrium model within a monopolistic competition setting: consumers have the love for variety, and each firm needs to pay both entry fixed costs to enter and fixed overhead costs to produce. I assume homothetic preferences over a continuum of goods for a representative consumer. Strategic interactions between firms do not arise due to the assumption of a continuum of goods. Each producer manufactures only one good. The relationship between a producer and a product is thus one-to-one. This particular setup means that the relevant profit-maximizing unit can be interpreted as a production line production.

Three types of firms co-exist in a market: new entrants, existing firms and quitters. Entry of new producers initiates product creation whereas exit of firms brings about product destruction. Product creation and product destruction match each other and happen simultaneously in each period due to the unique setting of the endogenized dynamics of firm productivity levels. Empirical evidences by Bernard, Redding and Schott (2010) show that product creation and product destruction 
among the U.S. manufacturing firms account for $46.6 \%$ and $44 \%$ of output, respectively. Therefore, I believe that the simultaneous entry and exit in my model is a reasonable assumption.

I sort firms by their productivity levels. New entrants with sufficiently high productivity levels self-select themselves into both the domestic market and international market. Firms with high enough productivity levels become multinationals; firms within certain low range of productivity levels only serve domestic markets; finally firms with in-between productivity levels of the FDI threshold and domestic producer threshold service foreign markets by exporting. This particular setting is based on the abundant empirical results that exporters are bigger and more productive than domestic firms.

Labor is exogenously given for an economy and the only production factor for firms. Consumers receive income from supplying labor and finance new entrants through the accumulation of shares in the portfolio of firms.

The remainder of the paper is organized as follows: in Section 3.1, I provide the background for model building. In Section 3.2, I develop the intertemporal and intratemporal models for consumers' demand, respectively. In section 3.3, I establish theoretical models for firms' production. In section 3.4, I describe firms' entry and exit in a closed economy. In section 3.5, I introduce firms' decision on international expansion. In section 3.6, I model the labor market for the open economy. In section 3.7, I analyze the aggregation and equilibrium conditions for the open economy. In section 3.8, I derive the national account and terms of trade.

\subsection{Model background}

The model has a standard Dixit-Stiglitz (1977) setting and incorporates firm level productivity differences and product differentiation. Following the model setup by 
Melitz (2003), I move away from a representative firm setting and abstract from some of the firm-level dynamic stochastic processes while preserving the essential and intuitive components that explain implications of heterogeneous firms in shaping certain industries both domestically and internationally.

I assume that firms have increasing return to scale cost structure and compete in a monopolistic market. Productivity differences between firms reflect not only cost differences among products but also differences in abilities to respond to exogenous shocks in the market. I also assume that all firms are forward looking and have full information about the future market including the entry decision. Firms face the initial productivity uncertainty before entry and do not know their productivity levels until entry.

As in Hopenhayn (1992b) and Melitz (2003), I restrict the equilibrium analysis to steady state equilibria in order to enforce stable aggregate environment overtime. And a steady state like this induces the simultaneous entry and exit of firms in every period.

\subsection{Model setup}

The world has two countries Home and Foreign; and each is populated by homogeneous consumers and occupied by a huge mass of prospective firms. Labor is fully employed in each period. Fully domestic labor mobility ensures wage equalization across firms within the same industry. Labor is prohibited from migrating to the foreign country to seek work opportunities. Therefore wage differentials across the two countries are allowed. Consumers can trade financial assets in the form of mutual funds derived from firm ownership. A representative consumer faces both intratemporal utility maximization and intertemporal utility maximization problems. Firms 
maximize profits and make decisions based on profit maximization. I then embed outcomes of these maximization problems into a general equilibrium structure of the economies.

\subsubsection{Demand}

i) Intratemporal problem

Each consumer consumes an aggregate good $C_{t} \equiv U_{t}$ defined over a continuum of goods $\Omega$. At any given time $t$, only a subset of goods is available. The preference is given by a C.E.S utility function over a continuum of goods indexed by $\omega$ for $\omega \in \Omega$. A representative consumer has a utility function with $\omega$ varieties as follows

$$
C_{t}=\left(\int_{0}^{\omega} q_{t}(\omega)^{\rho} d \omega\right)^{\frac{1}{\rho}}
$$

where $\omega$ also represents the mass of firms. Goods are substitutes with constant elasticity of substitution defined as $\sigma=\frac{1}{1-\rho}$ between any two goods, and $0<\rho<1$.

The utility function is subject to a budget constraint $\int_{0}^{\omega} p_{t}(\omega) q_{t}(\omega) d(\omega)=I_{t}$ where $I_{t}$ is the representative consumers income level at time $t$. The representative consumer solves her intratemporal utility maximization problem, and the optimal consumption decision over individual varieties is obtained as follows

$$
q_{t}(\omega)=C_{t}\left(\frac{p_{t}(\omega)}{p_{t}}\right)^{\frac{1}{\rho-1}}
$$

where $p_{t}(\omega)$ denotes the nominal price for good $\omega$ and $P_{t}$ is the aggregate price.

In equilibrium, the total revenue equals the total expenditure in an economy: $P_{t} C_{t}=\int_{0}^{\omega} p_{t}(\omega) q_{t}(\omega) d(\omega)$. Substituting the individual variety demand function $q_{t}(\omega)$ into the equation, the welfare-based aggregate price index can be obtained as follows:

$$
P_{t}=\int_{0}^{\omega}\left(p_{t}(\omega)^{\frac{1}{1-\rho} d(\omega)}\right)^{\frac{\rho-1}{\rho}}
$$


The expenditure or total revenue on a single variety is calculated as $r_{t}(\omega)=$ $p_{t}(\omega) q_{t}(\omega)=P_{t} C_{t}\left(\frac{p_{t}(\omega)}{p_{t}}\right)^{1-\sigma}$, where the ratio $\frac{p_{t}(\omega)}{p_{t}}$ is the benefit of an extra product variety. In real terms, the total revenue function can be written as $r_{t}^{r}(\omega)=$ $C_{t}\left(\frac{p_{t}(\omega)}{p_{t}}\right)^{1-\sigma}$. The expenditure on any individual variety is thus proportional to the total expenditure. The total expenditure or total revenue of an economy is $P_{t} C_{t}=\int_{0}^{\omega} r_{t}(\omega) d(\omega)$.

ii) Intertemporal problem

The representative consumer lives an infinite lifetime. In any period t, the consumer maximizes a lifetime expected utility function subject to the intertemporal budget constraint.

The representative consumer's expected lifetime utility function is defined as

$$
E \sum_{s-t}^{\infty} \beta^{s} U\left(C_{s}\right)
$$

where $\beta \in(0,1)$ is the subjective time preference discount factor. Because I assume that consumers are able to trade financial assets. In order to control for consumers' different tastes in financial risks, I assume a CRRA form period utility function $U\left(C_{s}\right)=\frac{1}{1-\theta} C_{s}^{1-\theta}$, in which $\theta>0, \theta \neq 1$ and $\theta=-C \frac{U^{\prime \prime}(C)}{U^{\prime}}$ is the constant coefficient of relative risk aversion.

Consumers own $x_{t}$ shares entering period $\mathrm{t}$ in a mutual fund of firm. ${ }^{1}$ The mutual fund pays a total profit in units of currency in each period equals to partial profits of all firms that earned in that period. In period $t$, the representative consumer purchases $x_{t+1}$ new shares before going into period $t+1$ as an investment. The total number of firms forming the mutual fund is $M_{t}$ (including new entrants) with average price $\tilde{z}_{t}$ and average profit $\bar{\pi}_{t}$. Firms pay dividends at time $t+1$. Consumers can also trade domestic bonds $(B)$ and foreign bonds $B^{*}$ that yield interest rates

\footnotetext{
${ }^{1}$ Mutual fund shares $x_{t}$ is introduced in in the sense of Ghironi and Melitz (2007) and Contessi (2007, 2015).
} 
$r_{t}$ and $r_{t}^{*}$, respectively. Consumers enter period $t$ with $x_{t}$ shares and receive income in forms of wage $W_{t} L_{t}$, dividends on share holdings $\bar{\pi}_{t} x_{t}$, the sale value of initial share position $\tilde{z}_{t} x_{t}$ and the interest payments from owning bonds. Consumers then allocate income resources between purchases of goods and purchases of new mutual fund shares. The intertemporal budget constraint can be written as

$$
\begin{aligned}
C_{t}+\tilde{z_{t+1}} M_{t} x_{t+1}+B_{t+1}+B_{t+1}^{*}= & W_{t} L_{t}+\tilde{z}_{t} M_{t} x_{t}+\bar{\pi}_{t} M_{t} x_{t}+ \\
& +\left(1+r_{t}\right) B_{t}+\frac{\varepsilon_{t} P_{t}^{*}}{P_{t}}\left(1+r_{t}^{*}\right) B_{t}
\end{aligned}
$$

where $\varepsilon_{t}$ is the nominal exchange rate, and $\frac{\varepsilon_{t} P_{t}^{*}}{P_{t}}=e_{t}$ is the real exchange rate.

To reduce the complexity in calculation while preserving essential parts for analysis, I assume that consumers do not trade bonds due to financial regulations in a closed economy. As a result, a representative consumer faces the intertemporal optimization problem as follows:

$$
\begin{gathered}
\max _{\left\{C_{t}, x_{t}\right\}} E_{t}\left(\sum_{t=0}^{\infty} \beta^{t} U_{t}\right) \\
\text { s.t. } C_{t}+\tilde{z}_{t+1} M_{t} x_{t+1}=W_{t} L_{t}+\bar{\pi}_{t} M_{t} x_{t}+\tilde{z}_{t} M_{t} x_{t}
\end{gathered}
$$

Consumers purchase $x_{t+1}$ shares of a mutual fund for a total of $M_{t} x_{t+1}$ shares in each period $t$. There is $M_{E, t}$ mass of new entrants financed by new investments in each period t and is implicitly embedded in $\tilde{z}_{t+1} M_{t} x_{t+1}$. Rearrange the budget constraint, I am able to obtain the national account of the autarky economy: $0=\left(W_{t} L_{t}+\right.$ $\left.\tilde{z}_{t} M_{t} x_{t}+\bar{\pi}_{t} M_{t} x_{t}\right)-\left(C_{t}+\tilde{z}_{t+1} M_{t} x_{t+1}\right)$. The zero net international investment position on the left hand side is equal to aggregate income minus the total expenditure of an economy on the right hand side. The solution to the intertemporal utility maximization problem yields an Euler equation for share holdings of the economy:

$$
\beta(1-\gamma) E_{t}\left(\frac{C_{t}}{C_{t+1}}\right)^{\theta}\left(z_{t+1}^{\tilde{1}}+\pi_{t+1}^{-}\right)=\tilde{z}_{t}+\bar{\pi}_{t}=\bar{v}_{t}
$$


The value $\bar{v}_{t}$ is the expected post-entry profit. The intertemporal consumption ratio

$\frac{C_{t}}{C_{t+1}}$ adds stochastic characteristics to the exogenously discount factor $\beta(1-\gamma)$, yielding a stochastic discount expression $\beta(1-\gamma)\left(\frac{C_{t}}{C_{t+1}}\right)^{\theta}$.

\subsection{Production}

There is a continuum of firms of which each produces a single variety $\omega$ for $\omega \in \Omega$. Production obeys the increasing returns to scale rule. Firms maximize profits and compete in a monopolistically competitive market. Entering the market requires sunk costs amounting to $f_{e}$. These sunk costs are unavoidable and can be treated as development and distribution costs. Labor is the only production factor and fixed by the total labor endowment $\bar{L}$. I assume full employment $L_{t}=\bar{L}$. Costs of all kinds are measured in labor units. It requires $l_{t}(\phi)=f_{t}+\frac{q_{\omega}}{\phi}$ labor units to produce $q_{t}(\omega)$ units of output of variety $\omega$ in period $t$. The variable $f_{t}$ is the fixed overhead cost in labor units and applies to every producing firm. Parameter $\phi$ is the idiosyncratic productivity level of a firm and time invariant. The unit cost of production is the real wage $W_{t} / P_{t} \equiv w_{t}$ and represents $w_{t}$ units of consumption basket $C_{t}$. The total cost function can be written as

$$
T C_{t}(\omega)=W_{t} L_{t}(\omega)=W_{t}\left(f_{t}+\frac{q_{t}(\omega)}{\phi}\right)
$$

The real total cost function can be calculated as $t c_{t}(\omega)=w_{t} f_{t}+\frac{w_{t} q_{t}(\omega)}{\phi}$ units of the consumption basket $C_{t}$. Component $w_{t} f_{t}$ is the real fixed cost and $\frac{w_{t} q_{t}}{\phi}$ is the real variable cost. The average cost function is computed as $a c_{t}(\omega)=\frac{w_{t} f_{t}}{q_{t}(\omega)}+\frac{w_{t}}{\phi}$ and the marginal cost function is $m c_{t}(\omega)=\frac{w_{t}}{\phi}$. The average cost function clearly implies an increasing return to scale property whereas the marginal cost function shows different marginal cost of production between products due to different $\phi$. 
Each firm maximizes its profits by maximizing the following equation: $\pi_{t}(\omega)=$ $p_{t}(\omega) q_{t}(\omega)-T C_{t}(\omega)$. The optimal price for each firm or variety is calculated as

$$
p_{\omega, t}(\phi)=\frac{W_{t}}{\phi \rho}=\frac{W_{t}}{\phi} \frac{\sigma}{\sigma-1}
$$

where $\frac{\sigma}{\sigma-1}=\frac{1}{\rho}$ is the markup over the marginal cost for each firm. The markup is independent of the number of varieties or firms. The optimal price in real terms can be written as $\varrho_{\omega, t}(\phi)=\frac{W_{t}}{\phi} \frac{\sigma}{\sigma-1}=\frac{W_{t}}{P_{t} \phi \rho}=\frac{w_{t} \sigma}{\phi(\sigma-1)}$ units of consumption basket.

Each firms revenue and profit can be calculated as follows

$$
\begin{gathered}
r_{\omega, t}(\phi)=p_{\omega, t}(\phi) q_{\omega, t}(\phi)=P_{t} C_{t}\left(P_{t} \frac{\phi}{W_{t}} \frac{\sigma-1}{\sigma}\right)^{\sigma-1}[t] \\
\pi_{\omega, t}(\phi)=\frac{r_{\omega, t}(\phi)}{\sigma}-W_{t} f_{t}
\end{gathered}
$$

In real terms the total revenue for variety $\omega$ is $r_{\omega, t}(\phi)=C_{t}\left(P_{t} \frac{\phi}{W_{t}} \frac{\sigma-1}{\sigma}\right)^{\sigma-1}$ units of consumption basket $C_{t}$ and the total profits for variety $\omega$ is $\pi_{\omega, t}^{*}(\phi)=\frac{\operatorname{tr}_{\omega, t}(\phi)}{\sigma}-w_{t} f_{t}$ of consumption basket $C_{t}$. Profits are returned to consumers as dividends and lent to new entrants as loans.

\subsection{Firm Entry and Exit in Autarky}

A large and unbounded pool of potential entrants decides whether to enter production, and all perspective entrants are identical prior to entry. These entrants correctly anticipate their expected future profits $v_{t}(\phi)$ as a function of the productivity level $\phi$. Upon entry, each new entrant draws a relative level of productivity $\phi$ from a common distribution of productivity denoted as $h(\phi)$. The common distribution is time-invariant and identical across the two countries. If $\phi$ is sufficiently low, a firm will exit immediately and never produce after invests $f_{e, t}$ labor units of sunk costs. If $\phi$ is high enough, the firm will produce but face $\gamma$ probability 
of exit-inducing shock in every period $t .^{2}$ A producing manufacturer produces at the same productivity level over time until it is hit by a bad shock $\gamma$ and forced to exit. Therefore the ex-ante survival probabilities are determined exogenously by both $h(\phi)$ and $\gamma$.

A successful entrant becomes a realized producer immediately in the same period. Prospective entrants in time $t$ calculate their value function that is the present discounted value of the expected stream of future profits:

$$
\begin{aligned}
v_{t}(\phi) & =\max \left\{0, E_{t} \sum_{s=t+1}^{\infty}[\beta(1-\gamma)]^{s}\left(\frac{C_{t}}{C_{s+t}}\right)^{\theta} \pi_{t}(\phi)\right\} \\
& =\max \left\{0, \beta(1-\gamma) E_{t}\left(\frac{C_{t}}{C_{s+t}}\right)^{\theta} \pi_{t}(\phi)\right\}
\end{aligned}
$$

The expression $\beta(1-\gamma) E_{t}\left(\frac{C_{t}}{C_{s+t}}\right)^{\theta}$ is a discount factor that reflects the optimal investment behavior of consumers who also take in to account firms exit $(1-\gamma)$.

The cutoff productivity level for successful new entrants is defined as $\phi^{c}=$ $\inf \left\{\phi: v(\phi)>0\right.$ and $\left.\pi\left(\phi^{c}\right)=0\right\}$. A new entrant is successful when $\phi>\phi^{c}$, and it produces immediately in the same period. So the ex-ante probability of successful entry can be written as $\operatorname{Pr}_{e}=1-H\left(\phi^{c}\right)$, where $H(\phi)$ is the cumulative density function of the common productivity distribution $h(\phi)$.

I denote $M_{e, t}$ as the mass of new entrants in each period t. As a result, the number of unsuccessful new entrants and successful new entrants can be calculated as $H\left(\phi^{c}\right) M_{e, t}$ and $\operatorname{Pr}_{e, t} M_{e, t}=1-H\left(\phi^{c}\right) M_{e, t}$, respectively. A firm may exit the domestic market for two reasons: as an unsuccessful entrant or as a bad luck producer. ${ }^{3}$ The mass of incumbent firms equals $M_{t}-\operatorname{Pr}_{e} M_{e, t}$, in which $M_{t}$ is the total number

\footnotetext{
${ }^{2}$ Lee and Mukoyama (2007) find that the exit rates throughout booms and recessions are very similar at 5.8 and 5.1 percent, resepectively. So the average exit rates are relative steady regardless of economic environment.

${ }^{3}$ Producers hit by the bad shock consequently exit including both successful new entrants and existing producers.
} 
of producers in equilibrium. The number of effective new entrants is then calculated as $(1-\gamma) \operatorname{Pr}_{e} M_{e, t}$. If $(1-\gamma) \operatorname{Pr}_{e} M_{e, t}=\gamma\left(M_{t}-\operatorname{Pr}_{e} M_{e, t}\right)$ or $\operatorname{Pr}_{e} M_{e, t}=\gamma M_{t}$, that is, the remaining new entrants completely replace the exit incumbent firms in each period, the exit process would not affect the equilibrium productivity distribution. Thus, in each period, the number of survival producers is established as follows:

$$
(1-\gamma) \operatorname{Pr}_{e} M_{e, t}+(1-\gamma)\left(M_{t}-\operatorname{Pr}_{e} M_{e, t}\right)=(1-\gamma) M_{t}
$$

Conditioning on successful entries, the expected value of productivity levels $\phi \in$ $\left[\phi^{c}, \infty\right]$ is established as

$$
\bar{\phi}_{t}\left(\phi^{c}\right)=\left(\int_{\phi^{c}}^{\infty} \phi^{\sigma-1} \frac{h(\phi)}{1-H\left(\phi^{c}\right) d \phi}\right)^{\frac{1}{\sigma-1}}
$$

Since firms are forward looking and have full information about the market, the expected stream of future profits becomes the realized average profits:

$$
\bar{v}_{t}(\phi)=\beta(1-\gamma)\left(\frac{C_{t}}{C_{t+1}}\right)^{\theta} \bar{\pi}_{t}\left(\bar{\phi}\left(\phi^{c}\right)\right)
$$

Net free entry condition is such that potential entrants evaluate the net value of entry $\left(v_{e, t}\right)$ against the fixed sunk entry cost $\left(f_{e, t}\right)$ in each period. No firm would want to enter if the net value of a successful entry is less than the fixed entry sunk cost. So long as the mass of new entrants is positive, the following Free Entry Condition holds

$$
\begin{aligned}
& \left(1-H\left(\phi^{c}\right)\right) \beta(1-\gamma)\left(\frac{C_{t}}{C_{t+1}}\right)^{\theta} \bar{\pi}_{t}\left(\bar{\phi}\left(\phi^{c}\right)\right)=W_{t} f_{e, t}=\bar{v}_{t}(\phi) \\
& \rightarrow \bar{\pi}_{t}\left(\bar{\phi}\left(\phi^{c}\right)\right)=\frac{W_{t} f_{e, t}}{\left(1-H\left(\phi^{c}\right)\right) \beta(1-\gamma)}\left(\frac{C_{t}}{C_{t+1}}\right)^{-\theta}
\end{aligned}
$$

The Free Entry Condition in real terms is thus $\bar{\pi}_{t}^{r}\left(\bar{\phi}\left(\phi^{c}\right)\right)=\frac{W_{t} f_{e, t}}{\left(1-H\left(\phi^{c}\right)\right) \beta(1-\gamma)}\left(\frac{C_{t}}{C_{t+1}}\right)^{-\theta}$. The real average profit function can be written as $\operatorname{bar}_{t}^{r}(\bar{\phi}(\phi))=\frac{\operatorname{tr}_{\omega, t}(\phi)}{\sigma}-w_{t} f_{t}$, in which $\frac{\bar{t} r_{\omega, t}(\phi)}{\sigma}=\left(\frac{\bar{\phi}}{\phi^{c}}\right)^{\sigma-1} \operatorname{tr}_{t}\left(\phi^{c}\right)$ and $t r_{t}\left(\phi^{c}\right)=\sigma w_{t} f_{t}$. Therefore, the second relationship between the real average profit and the cutoff productivity can be calculated 
as follows:

$$
\bar{\pi}_{t}\left(\bar{\phi}\left(\phi^{c}\right)\right)=\frac{\overline{t r}_{\omega, t}(\phi)-t r_{t}\left(\phi^{c}\right)}{t r_{t}\left(\phi^{c}\right)} w_{t} f_{t}
$$

\subsubsection{Equilibrium in autarky}

The threshold productivity level $\phi^{c}$, aggregated price $P_{t}$ and aggregated total revenues $T R_{t}$ determine a stationary equilibrium, which must satisfy both the Free Entry Condition and the Zero Cutoff Profit Condition calculated previously. In equilibrium, all aggregate variables stay constant without the influence of outside shocks. The number of firms is determined by aggregated variables in equilibrium.

Since the distribution of productivity levels $h(\phi)$ remains constant throughout all periods, an industry comprised of $M$ firms (in equilibrium) with any distribution of productivity levels $h(\phi)$ that yields the same average productivity level $\bar{\phi}$ induces the same aggregate outcome as $M$ firms share the same productivity level $\phi=\bar{\phi}$. Aggregated variables obtained in equilibria depend on the number of firms. I denote average revenues and average profits as $\bar{r}=\frac{T R}{M}$ and $\bar{\pi}=\frac{\Pi}{M}$, respectively.

The detailed description of equilibrium and labor market is discussed in later sections where international expansion is introduced.

\subsection{International Expansion}

All domestic firms in autarky economies (Home and Foreign) have the opportunity to engage in the international market through two viable strategies: exporting to the overseas market (export strategy) or building a plant and selling products in the host country (FDI strategy). Both strategies happen after firms gain knowledge of their productivity levels. In addition to selling in a foreign country, both exporters and multinational firms (MNEs) continue to sell domestically. 
I consider an open economy with trade costs. In each period, exporters need to pay fixed exporting costs $w_{t} f_{x, t}$ units of domestic consumption as well as the iceberg unit transport $\operatorname{costs} \tau_{t}>1$; whereas multinational enterprises entail fixed costs of $f_{m, t}=w_{t}^{*} f_{m, t}^{*}$ units of foreign consumption to build a plant in the host country.

Export sales in the destination are converted back to domestic currency by nominal exchange rate $\varepsilon_{t}$. Multinational firms hire foreign labor to produce therefore pay foreign workers $W_{t}^{*}$ amount nominal wages in local currency. So the Home exporters and Home MNEs optimal prices in real terms are calculated as follows

$$
\varrho_{x, t, \omega}(\phi)=\frac{\tau_{t} w_{t}}{\phi} \frac{\sigma}{\sigma-1}, \varrho_{m, t, \omega}(\phi)=\frac{w_{t}^{*}}{\phi} \frac{\sigma}{\sigma-1}
$$

In addition to imports from Home country, Foreign consumers also have access to domestically produced varieties charged at $\varrho_{\omega, t}^{*}=\frac{w_{t}^{*}}{\phi} \frac{\sigma}{\sigma-1}$. The Foreign local producers optimal prices are different from the Home multinationals optimal prices in Foreign in a sense of productivity differentials. In each period, Home exporters earn nominal profits $\pi_{\omega, t}(\phi)+\max \left\{\pi_{\omega, t}(\phi)\right\}$. And Home multinationals earn nominal profits $\pi_{\omega, t}(\phi)+\max \left\{0, \pi_{m, t, \omega}(\phi)\right\}$.

When countries open up and engage in international sales, three ex-ante survival probability conditions co-exist in every period for successful entrants based on three different cutoff productivity levels. The ex-ante probability that one of these successful entrants will become a multinational is $\operatorname{Pr}_{m}=\frac{1-H\left(\phi_{m}^{c}\right)}{1-H\left(\phi^{c}\right)}$. The ex-ante probability that one of these successful entrants will export is $\operatorname{Pr}_{x}=\frac{H\left(\phi_{m}^{c}\right)-H\left(\phi_{x}^{c}\right)}{1-H\left(\phi^{c}\right)}$. The domestic only producers have an ex-ante probability of $\operatorname{Pr}_{D}=\frac{H\left(\phi_{x}^{c}\right)-H\left(\phi^{c}\right)}{1-H\left(\phi^{c}\right)}$. Therefore, the total mass of firms or varieties available in Home is $M_{T, t}=\operatorname{Pr}_{D} M_{t}+$ $\operatorname{Pr}_{x}^{*} M_{t}^{*}+\operatorname{Pr}_{m}^{*} M_{t}^{*}$. And the total mass of firms or varieties available in Foreign is $M_{T, t}^{*}=\operatorname{Pr}_{D}^{*} M_{t}^{*}+\operatorname{Pr}_{x}^{*} M_{t}+\operatorname{Pr}_{m}^{*} M_{t}$ 
Recall firms' value function is $v_{t}(\phi)=\max \left\{0, \beta(1-\gamma) E_{t}\left(\frac{C_{t}}{C_{t+1}}\right)^{\theta} \pi_{t}(\phi)\right\}$.Potential exporters and prospective multinationals evaluate their updated value function to decide whether to enter the international market. For exporters, the cutoff productivity $\phi_{x}^{c}$ is such that $\phi_{x}^{c}=\inf \left\{\phi: \phi \geq \phi_{x}^{c}\right.$ and $\left.\pi_{x}(\phi)>0\right\}$. By a similar reasoning, the cutoff productivity $\phi_{m}^{c}$ for multinationals is defined as $\phi_{m}^{c}=\inf \{\phi$ : $\phi \geq \phi_{m}^{c}$ and $\left.\pi_{m}(\phi)>0\right\}$

If $\phi_{m}^{c}=\phi_{x}^{c}=\phi^{c}$, all producers become multinationals. If $\phi_{m}^{c}=\phi_{x}^{c}>\phi^{c}$, some firms whose productivities fall in the range of $\phi^{c}<\phi<\phi_{m}^{c}=\phi_{x}^{c}$ produce and sell only in the domestic market. If $\phi_{m}^{c}>\phi_{x}^{c}>\phi^{c}$, firms with productivity $\phi_{x}^{c}<\phi<\phi_{m}^{c}$ become exporters who produce in Home and sell in both the domestic market and Foreign market. Only firms in the highest possible productivity range of $\phi_{m}^{c}<\phi$ adopt the FDI strategy and become multinational firms who invest in host country and produce and sell in both countries. Therefore, the three Zero Cutoff Conditions for domestic producers, exporters and multinational firms are computed as $\bar{\pi}_{D, t}\left(\phi^{c}\right)=0, \bar{\pi}_{x, t}\left(\phi_{x}^{c}\right)=0$, and $\bar{\pi}_{m, t}\left(\phi_{m}^{c}\right)=0$, respectively.

In the presence of international businesses, the average productivity levels can be defined separately for the three groups of firms. I denote domestic only producers productivity level as $\phi_{D}$, exporters productivity level as $\phi_{x}$, and multinational firms productivity level as $\phi_{m}$. The corresponding equations are established as follows

$$
\begin{aligned}
\bar{\phi}_{D}\left(\phi^{c}\right) & =\left(\int_{\phi^{c}}^{\phi_{x}^{c}} \phi^{\sigma-1} \frac{h(\phi)}{H\left(\phi_{x}^{c}\right)-H\left(\phi^{c}\right)} d \phi\right)^{\frac{1}{\sigma-1}} \\
& =\left(\int_{\phi_{x}^{c}}^{\phi_{m}^{c}} \phi^{\sigma-1} \frac{h(\phi)}{H\left(\phi_{m}^{c}\right)-H\left(\phi_{x}^{c}\right)} d \phi\right)^{\frac{1}{\sigma-1}} \\
\bar{\phi}_{m}\left(\phi^{c}\right) & =\left(\int_{\phi_{m}^{c}}^{\infty} \phi^{\sigma-1} \frac{h(\phi)}{1-H\left(\phi_{m}^{c}\right)} d \phi\right)^{\frac{1}{\sigma-1}}
\end{aligned}
$$

Regardless of their engagement in the international market, exporters and multinationals always produce and sell in the domestic market. All firms face the common productivity distribution $h(\phi)$ before entry and the same bad shock probability $\delta$ af- 
ter entry. All exporters face the same fixed entry export costs and iceberg unit cost, and all multinational enterprises have the same fixed entry costs in the host country. Therefore, the profit functions for domestic producers, exporters and multinational firms can be written as

$$
\begin{aligned}
& \pi_{d, t}(\phi)=\frac{r_{D, t}(\phi)}{\sigma}-W_{t} f_{t} \\
& \pi_{E X, t}(\phi)=\frac{r_{D, t}(\phi)+r_{x, t}(\phi)}{\sigma}-W_{t} f_{x, t} \\
& \pi_{M, t}(\phi)=\frac{r_{D, t}^{*}(\phi)+r_{m, t}^{*}(\phi)}{\sigma}-W_{t}^{*} f_{x, t}^{*}
\end{aligned}
$$

The real average profits earned by total domestic sales, total exports sales and FDI sales can be established as $\bar{\pi}_{D, \omega, t}^{r}\left(\phi^{c}\right)=\frac{\overline{t r}_{D, \omega, t}\left(\phi^{c}\right)}{\sigma}-w_{t}^{*} f_{t}^{*}$, respectively.

The average profits for all Home firms conditioned on successful entry at time t can then be written as $\bar{\pi}_{t}(\phi)=\frac{1}{1-H\left(\phi^{c}\right)} \bar{\pi}_{D, t}(\phi)+\frac{H\left(\phi_{m}^{c}\right)-H\left(\phi_{x}^{c}\right)}{1-H\left(\phi^{c}\right)} \bar{\pi}_{x, t}(\phi)+\frac{1-H\left(\phi_{m}^{c}\right)}{1-H\left(\phi^{c}\right)} \bar{\pi}_{m, t}(\phi)$. The zero profit cutoff conditions yield the real average profit function as a function of cutoff productivity levels:

$$
\begin{aligned}
\bar{\pi}_{t}^{r}(\phi)= & w_{t} f_{t}\left[\left(\frac{\bar{\phi}\left(\phi^{c}\right)}{\phi^{c}}\right)^{\sigma-1}-1\right]+w_{t} f_{x, t}\left[\left(\frac{\bar{\phi}\left(\phi_{x}^{c}\right)}{\phi_{x}^{c}}\right)^{\sigma-1}-1\right]+ \\
& +w_{t}^{*} f_{t}^{*}\left[\left(\frac{\bar{\phi}\left(\phi_{m}^{c}\right)}{\phi_{m}^{c}}\right)^{\sigma-1}-1\right]
\end{aligned}
$$

The free entry condition for an open economy is still the same in that potential firms do not know their productivity levels until they decide to enter and pay the fixed entry costs. So the relationship between the average profit and cutoff entry productivity level in the free entry condition is the same as before and given as $\bar{\pi}\left(\bar{\phi}\left(\phi^{c}\right)\right)=\frac{W_{t} f_{e, t}}{1-H\left(\phi^{c}\right) \beta(1-\gamma)}\left(\frac{C_{t}}{C_{t+1}}\right)^{-\theta}$.

\subsection{Labor Market in the open economy}

Labor market conditions do not change when the autarky economy makes a transition to an open economy by engaging in international market via trade or FDI. In 
an open economy, the aggregate income needs not necessarily equal the payments to all labor supply of the economy.

I assume that regardless of their success status in each period, new entrants to the domestic market raise the capital amounts to $w_{t} f_{t}$ which provides a random return of $\pi_{t}(\phi)$ for $\phi>\phi^{c}$ or zero for $\phi \leq \phi^{c}$. Entrants to the international market always make positive profits thus do not face such uncertainty. These entrants have realized productivity levels that are greater than the cutoff productivity $\phi^{c}$ and therefore self-select themselves into the international market.

I assume that labor supply is inelastic and the labor size is fixed and exogenously determined for a country. The fixed labor endowment $\bar{L}$ consists of two types: the fixed entry labor investment $L_{e, t}=M_{E, t} f_{e, t}$ and the production labor $L_{p, t}=l_{t}(\omega)$. Labor market equilibrium requires that the two components of labor demand sum to aggregate labor supply: $\bar{L}=L_{e, t}+L_{p, t}$. The profit maximization equation yields a relationship between the real total revenue and real total payments to labor:

$$
w_{t} \bar{L}=t r_{t}^{r}-\Pi_{t}^{r}+L_{e, t}
$$

In each period, $\gamma M_{T}$ mass of firms including both the successful entrants and the incumbents exit the market. In equilibrium, the mass of successful new entrants $\left(1-H\left(\phi^{c}\right)\right) M_{E, t}$ must be matched by the number of firms hit by the bad shock $\gamma M_{T}$. I can then establish the relationship between the mass of successful new entrants $M_{E, t}$ and total number of firms: $\left(1-H\left(\phi^{c}\right)\right) M_{E, t}=\gamma M_{T}$, which yields $M_{E, t}=$ $\frac{\gamma M_{T}}{\left(1-H\left(\phi^{c}\right)\right)}$. Market clearing condition requires that the fixed new entry investment to be the exact amount paid to the fixed entry investment labor: $w_{t} L_{e, t}=w_{t} M_{E, t} f_{e, t}$. Recall the free entry condition in which the relationship between average profits $\bar{\pi}_{t}$ and cutoff productivity level $\phi^{c}$ is established as $\bar{\pi}_{t}\left(\bar{\phi}\left(\phi^{c}\right)\right)=\frac{W_{t} f_{e, t}}{1-H\left(\phi^{c}\right) \beta(1-\gamma)}\left(\frac{C_{t}}{C_{t+1}}\right)^{-\theta}$. Using these equations, a relationship between the aggregate profit and the fixed 
entry labor cost can be derived as

$$
\gamma \Pi_{t}=\frac{w_{t} L_{e, t}}{\beta(1-\gamma)}\left(\frac{C_{t}}{C_{t+1}}\right)^{\theta}
$$

The expression $\beta(1-\gamma)\left(\frac{C_{t}}{C_{t+1}}\right)$ is a discount factor that reflects the optimal investment behavior of consumers in equilibrium. This relationship shows that in each period the lost profits due to bad shock equal the payments to labor of new firms taking into account the discount factor to keep the economy in equilibrium. This means that the amount needed to finance new firms in each period sums to the lost profits $\gamma \Pi_{t}$. The remaining profits $(1-\gamma) \Pi_{t}$ goes back to labor in form of dividends. This equation clearly shows that profits earned in each period are affected by optimal intertemporal consumption, the investment decisions and the time preference parameter $\beta$.

\subsection{Aggregation and equilibrium in the open economy}

The aggregate price, aggregate revenues, aggregate profits and market demand for the open economy depend on the number of firms in equilibrium and their respective expressions can be established as follows:

$$
\begin{aligned}
& P_{t}=\left(\int_{0}^{\infty} p_{t}\left(\phi_{t}\right)^{1-\sigma} h(\phi) d \phi\right)^{\frac{1}{1-\sigma}}=M_{T}^{\frac{1}{1-\sigma}} p_{t}\left(\bar{\phi}_{t}\right) \\
& T R_{t}=M_{T} \int_{0}^{\infty} r_{t}(\phi) h(\phi) d_{\phi}=M_{T} r_{t}\left(\bar{\phi}_{t}\right) \\
& \Pi_{t}=M_{T} \int_{0}^{\infty} \pi_{t}(\phi) h(\phi) d \phi=M_{T} \pi_{t}\left(\bar{\phi}_{t}\right) \\
& C_{t}=\left(M_{T} \int_{0}^{\infty} q_{t}\left(\phi_{t}\right)^{\frac{\sigma-1}{\sigma}} h(\phi) d \phi\right)^{\frac{\sigma}{\sigma-1}}=M_{T}^{\frac{\sigma}{\sigma-1}} q_{t}\left(\bar{\phi}_{t}\right)
\end{aligned}
$$

The combined aggregate productivity in equilibrium is calculated as

$$
\begin{aligned}
\bar{\phi}_{t}= & \frac{1}{M_{T}}\left(\bar{\phi}_{t}^{\sigma-1} M+\frac{H\left(\phi_{m}^{c}\right)-H\left(\phi_{x}^{c}\right)}{1-H\left(\phi^{c}\right)}\right)\left(\phi_{x, t}^{c}\right)^{\sigma-1} M+ \\
& +\frac{1-H\left(\phi_{m}^{c}\right)}{1-H\left(\phi^{c}\right)}\left(\phi_{m, t}^{c}\right)^{\sigma-1} M
\end{aligned}
$$


where $\phi_{x, t}^{c}=\tau_{t}\left(\frac{f_{x, t}}{f_{t}}\right)^{\frac{1}{\sigma-1}} \phi^{c}$ and $\phi_{m, t}^{c}=\left(\frac{W_{t}^{*}}{W_{t}^{*}}\right)^{\frac{\sigma}{1-\sigma}}\left(\frac{f_{t}^{*}}{f_{t}}\right) \phi^{c}$. An increase in the number of firms implies that consumers derive more welfare from spending a given nominal amount.

Equilibrium mass of firms is determined by these aggregate conditions. In equilibrium, $M_{T}$ mass of firms shares the same weighted average of the productivity level $\bar{\phi}$ as the average price, average revenues, average profits and aggregate demand and all depend on the average productivity. The combined total mass of varieties or firms in equilibrium is thus

$$
M_{T}=\left(1+\frac{H\left(\phi_{m}^{c}\right)-H\left(\phi_{x}^{c}\right)}{1-H\left(\phi^{c}\right.}+\frac{1-H\left(\phi_{m}^{c}\right)}{1-H\left(\phi^{c}\right)}\right) M_{t}
$$

$M_{t}$ is the total number of firms that operate in the domestic market in equilibrium. And $M_{t}$ can be calculated using the aggregate revenue condition $M_{t}=\frac{T R_{t}}{\bar{r}_{t}}$ as follows

$$
M_{t}=\frac{W_{t} \bar{L}+1-\left(\frac{1-\gamma}{r_{t}}\right) M_{E, t} f_{e, t}}{\sigma\left(\bar{\pi}_{t}+W_{t} f_{t}+\frac{H\left(\phi_{m}^{c}\right)-H\left(\phi_{x}^{c}\right)}{1-H\left(\phi^{c}\right)} W_{t} f_{x, t}+\frac{1-H\left(\phi_{m}^{c}\right)}{1-H\left(\phi^{c}\right)} W_{t}^{*} f_{t}^{*} \varepsilon_{t}\right)}
$$

Comparing with the number of firms operating in equilibrium of an autarky economy, the equilibrium number of varieties in an open economy shrinks due to the exit of domestic firms with lowest levels of productivity.

The engagement in the international markets by firms with high productivity levels induces an increase in the cutoff productivity level from the autarky level $\phi_{A}^{c}$ to an open economy level $\phi_{I}^{c}$, as a result the average profits per firm increase. Recall the shared free entry condition for both market regimes $\bar{\pi}_{t}\left(\bar{\phi}\left(\phi^{c}\right)\right)=\frac{\gamma r_{t} W_{t} f_{e, t}}{\left(1-H\left(\phi^{c}\right)\right)(1-\gamma)}$. As the cutoff productivity level $\phi^{c}$ for entering goes up, the ex-ante probability of successful entry $1-H\left(\phi^{c}\right)$ decreases. Firms who draw productivity level $\phi^{c}$ between $\phi_{A}^{c}<\phi^{c}<\phi_{I}^{c}$ exit foreign market immediately upon entry without producing. And former incumbents whose productivity level $\phi^{c}$ falls in between $\phi_{A}^{c}$ and $\phi_{I}^{c}$ also leave the foreign market due to negative profits earned. This is also the reason behind the 
shrinking of the number of equilibrium domestic only producers. Firms with high enough productivity levels enter the international market as exporters $\left(\phi^{c}>\phi_{x}^{c}\right)$ or multinationals $\left(\phi^{c}>\phi_{m}^{c}\right)$. The entry and exit of firms and the reallocation of market shares toward more efficient firms combined increase aggregate productivity gain in an open economy. Therefore, the average profits in an open economy are higher than the average profits in a closed economy. Furthermore, the decrease in the number of domestic firms is more than offset by the number of firms entering into the exporting market and foreign market via FDI. Overall the equilibrium number of total firms $M_{T}$ in the open market is bigger than the equilibrium number of firms $\left(M_{t}\right)$ in autarky as

$$
M_{T}=\left(1+\frac{H\left(\phi_{m}^{c}\right)-H\left(\phi_{m}^{c}\right)}{1-H\left(\phi^{c}\right)}+\frac{1-H\left(\phi_{m}^{c}\right)}{1-H\left(\phi^{c}\right)}\right) M_{t}>M_{t} .
$$

Benefits are not equally distributed among firms that engage in international businesses for these firms have higher fixed costs than firms that compete only domestically. Allowing the engagement in international market via trade and FDI is costly to an economy. The most efficient firms with sufficiently high productivity levels $\left(\phi_{m}^{c}<\phi^{c}\right)$ gain the most by breaking into a new market as multinationals in the foreign country as well as continuing to sell in domestic market hence gaining market shares. By the same reasoning, exporters $\left(\phi_{x}^{c}<\phi^{c}<\phi_{m}^{c}\right)$ obtain more market shares by accessing the foreign market. There exists a cutoff productivity level $\phi^{\Delta}>\phi_{m}^{c}$ that partitions gainers and losers in the international market. Firms with $\phi^{c} \geq \phi^{\Delta}$ see their profits increase whereas firms with $\phi^{c}=\phi_{m}^{c}$ lose profits while gaining market share. Firms with low efficiency or sufficiently low productivity between $\phi_{A}^{c}<\phi^{c}<\phi_{m}^{c}$ exit the market due to negative profits. Market shares of exit firms drop to zero. Therefore, multinational firms gain the most in market shares. 
To further elaborate, I compare firms' revenues in three different markets: domestic, export and foreign for FDI. Two types of firms sell in domestic market: the domestic only producers and firms with international businesses. The average domestic sales $r_{d, t}(\phi)$ in an open economy are smaller than the average domestic revenues $r_{A, t}(\phi)$ obtained in an autarky due to the exit of low efficient firms and reallocation of sales to foreign markets of exporters and multinationals. Individual firm that only operates domestically thus incur a total revenue loss. But the overall average sales $r_{d, t}(\phi)+r_{x, t}(\phi)+r_{m, r}(\phi)$ of all firms of a country in the open economy are larger than the autarky revenues $r_{A, t}(\phi)$.

\subsection{National account and Terms of Trade}

Rearranging the budget constraint equation, I can obtain the national account for the autarky economy: $0=\left(w_{t} L_{t}+\tilde{z}_{t} M_{t} x_{t}+\bar{\pi}_{t}^{r} M_{t}\right)-\left(C_{t}+\tilde{z}_{t} M_{t} x_{t+1}\right)$. The net international investment position is equal to aggregate income minus the total expenditure of an economy and is zero in a closed economy. In equilibrium, I impose the condition $x_{t}=x_{t+1}$ and normalize each value of the two variables to one. The GDP identity for the closed economy can thus be established as $G D P \equiv C_{t}+\tilde{z}_{t} M_{t}=w_{t} L_{t}+\bar{v}_{t} M_{t}$.

Total consumption $C_{t}$ plus new investment $\tilde{z}_{t} M_{t}$ must equal the total income. New investments include the finance of new firms or varieties and the new purchased shares by consumers. Both types of investments are implicitly embedded in the national account identity. The new purchase of new shares is essentially a transfer of income from the purchaser to the receiver. Therefore, the total expenditure is $C_{t}+\tilde{z}_{t} M_{E, t}$ after taking into account the net transfer of incomes. The revised GDP identity of the closed economy is therefore $G D P \equiv C_{t}+\tilde{z}_{t} M_{E, t}=w_{t} L_{t}+$ $\bar{v}_{t} M_{t}$. This updated GDP equation tells me that the allocation of resources between 
consumption and investment of the economy is reflected in the allocation of labor between the production sector and the new entrant sector.

According to the definition by the IMF, Current Account consists of three components: net exports, primary income and secondary income. ${ }^{4}$ My model suggests null secondary income. As a result, the Current Account of the open economy is the sum of the net exports and the net repatriation of FDI profits (primary income). The net export is equal to exports or foreign consumption of domestic goods minus imports or domestic consumption of foreign goods, and it can be calculated as: $e_{t} C_{t}^{*} M_{x, t}\left(\bar{\varrho}_{x, t}\right)^{1-\sigma}-M_{x, t}^{*}\left(\bar{\varrho}_{x, t}^{*}\right)^{1-\sigma} C_{t}$, where $e_{t}=\frac{P_{t}^{*}}{P_{t}}$ is the real exchange rate. The primary income or the net recipients of domestic MNEs can be computed as: $M_{m, t} \pi_{m, t}^{-}-e_{t} M_{m, t}^{*} \bar{\pi}_{m, t}^{*}$. Combining the two components, the Current Account can then be established as follows

$$
C A_{t}=\left(e_{t} C_{t}^{*} M_{x, t}\left(\bar{\varrho}_{x, t}\right)^{1-\sigma}\right)-M_{x, t}^{*}\left(\bar{\varrho}_{x, t}^{*}\right)^{1-\sigma} C_{t}+\left(M_{m, t} \bar{\pi}_{m, t}-e_{t} M_{m, t}^{*} \bar{\pi}_{m, t}^{*}\right) .
$$

The terms of trade $\left(\right.$ tot $\left._{t}\right)$ are endogenously determined in my model and are defined as the price of imports per unit of exports of the economy: $t_{t}=\frac{e_{t} \bar{\varrho}_{x, t}}{\bar{\varrho}_{x, t}^{*}}$. The average prices in the equation can be treated as trade-weighted indices of average prices. An increase in the terms of trade $t_{0} t_{t}$ represents improved international trade terms for the home country so per unit of exports sold can purchase more imports.

\subsection{Conclusion}

I develop a dynamic, stochastic, general equilibrium model and endogenize FDI and export as two alternative strategies for firms' international expansion options in a two-country world. The model has a standard Dixit-Stiglitz (1977) and Melitz (2003) model setup and incorporates firm level productivity differences and product

\footnotetext{
${ }^{4}$ Please refer to the Balance of Payment manual of the IMF for detailed information.
} 
differentiation. I separate firms into four categories based on their productivity levels. I show that the average domestic sales in an open economy are smaller than the average domestic revenues obtained in an autarky due to the exit of lowest productivity firms and reallocation of sales to foreign markets of exporters and multinationals. But the overall average sales of all firms in the open economy are larger than those in the closed economy. In addition, the equilibrium number of total firms in the open market is bigger than the equilibrium number of firms in the autarky. I also show that benefits incurred by international engagement are not equally distributed among firms. The highest productivity firms gain the most by breaking into a new market as multinationals. The second highest productivity firms become exporters and obtain the second largest market share. The third highest productivity firms only serve the domestic market. And the lowest productivity firms exit the market. 


\section{BIBLIOGRAPHY}

[1] Becker, S.O., and Ichino, A. (2002). Estimation of average treatment effects based on propensity scores, The Stata Journal, No.4, pp. 358-377.

[2] De Loecker, J. (2007). Do Exports Generate Higher Pr4oductivity? Evidence from Slovenia. Journal of International Economics, Vol.73, pp. 69-98.

[3] Van Biesebroeck, J. (2003). Exporting Raises Productivity in Sub-Saharan African Manufacturing Plants, NBER WP 10020.

[4] James J. Heckman. and Petra Todd. (1998). Matching As An Econometric Evaluation Estimator, Review of Economic Studies, Vol.65, 261-294.

[5] Imbens, G. and Abadie, A., Drukker, D. and Herr, J. (2001). Implementing Matching Estimators for Average Treatment E ects in Stata, STATA Journal, Vol.1, 1-18.

[6] Alvarez, R. and Lopez, R. (2004). Exporting and Performance: Evidence from Chilean Plants, Mimeo, Indiana University.

[7] Bernard, Andrew B. and J. Bradford Jensen (1999). Exceptional Exporter Performance: Cause, Effect or Both? Journal of International Economics, Vol.47 (1), pp. 1-25.

[8] Bernard, A. B. and Wagner, J. (1997). Exports and Success in German Manufacturing, Weltwirtschaftliches Archiv, Vol.133 (1), pp. 134-157.

[9] Aw, B. Y. and A.R. Hwang. (2000). Productivity and the export market: A firm-level analysis, Journal of Development Economics, Vol.47, pp. 313-332.

[10] Aw, B. Y., Chung, S. and Roberts, M. (2000). Productivity and Turnover in the Export Market: Micro Evidence from Taiwan and South Korea, The World Bank Economic Review.

[11] Aw, Y.B. Mark J. Roberts. and Winston, T. (2007). Export Market Participation, Investments in R\&D and Worker Training, and the Evolution of Firm Productivity, The World Economy, Vol.30 (1), pp. 83-104.

[12] Blalock, G. and Gertler, G. (2004). Learning from exporting revisited in a less developed setting, Journal of Development Economics, Vol.75 (2), pp. 397-416. 
[13] Clerides, S.K., Lach, S. and Tybout, J.K. (1998). Is Learning by Exporting Important? Micro-Dynamic Evidence from Colombia, Mexico, and Morocco, The Quarterly Journal of Economics, Vol.113 (3), pp. 903-947.

[14] Damijan, J.P., Glazar, M., Prasnikar, J. and Polanec, S. (2004a). Export vs. FDI Behavior of Heterogenous Firms in Heterogenous Markets: Evidence from Slovenia, LICOS DP 147.

[15] Ericson, R. and Pakes, A. (1995). Markov Perfect Industry Dynamics: A Framework for Empirical Work, Review of Economic Studies, Vol.62 (1), pp. 53-82.

[16] Fernandez, A.M. and Isgut, A.E. (2005). Learning-by-Doing, Learning-byExporting, and Productivity: Evidence from Colombia, mimeo World Bank.

[17] Girma, S., D. Greenaway and R. Kneller (2002). Does Exporting Lead to Better Performance? A Microeconometric Analysis of Matched Firms, GEP Research Paper.

[18] Isgut, A. (2001). What's Different About Exporters? Evidence from Colombian Manufacturing, Journal of Development Studies, Vol.37 (5), pp. 57-82.

[19] Keller, W. and Yeaple, S.R. (2003). Multinational Enterprises, International Trade, and Productivity Growth: Firm-Level Evidence from the United States, NBER WP 9504.

[20] Levinsohn, J. and Petrin, A. (2003). Estimating Production Functions Using Inputs to Control for Unobservables, Review of Economic Studies, Vol.70 (2), pp. 317-342.

[21] Melitz, M. (2003). The Impact of Trade on Intra-Industry Reallocations and Aggregate Industry Productivity, Econometrica, Vol.71 (6), pp. 1695-1725.

[22] Olley, S. and Pakes, A. (1996). The Dynamics of Productivity in the Telecommunications Equipment Industry, Econometrica, Vol.64 (6), pp. 1263-1298.

[23] Pavcnik, N. (2002). Trade Liberalization, Exit, and Productivity Improvement: Evidence from Chilean Plants, Review of Economic Studies, Vol.69 (1), pp. 245-276.

[24] Rosenbaum, P., and D. Rubin. (1983). The Central Role of the Propensity score in Observational Studies for Causal Effects, Biometrika, Vol.70 (1), pp. 41-55. 
[25] Van Biesebroeck, J. (2004). Robustness of Productivity Estimates, NBER WP 10303.

[26] Wagner, J. (2005). Exports and Productivity: A Survey of the Evidence from Firm-Level Data, World Economy, Vol.30 (1), pp. 60-82.

[27] Wagner, J. (2005). The causal effects of exports on firm size and labor productivity: First evidence from a matching approach, HWWA DP 155.

[28] Wagner, J. (2005). Exports, Foreign Direct Investment, and Productivity: Evidence from German Firm Level Data, WP 8, University of Luneburg.

[29] World Bank (1993). The East Asian Miracle: Economic Growth and Public Policy, New York: Oxford University Press for the World Bank.

[30] Eric J. Bartelsman. (1998). Productivity Dynamics: U.S. Manufacturing Plants, 19721986, Journal of Productivity Analysis, Vol.9, pp. 5-34.

[31] Tybout, J. R. and M. Daniel Westbrook (1995). Trade Liberalization and Dimensions of Efficiency Change in Mexican Manufacturing Industries, Journal of International Economics, Vol.31, pp. 53-78.

[32] De Loecker, J. and Warzynski, F. (2012). Markups and Firm-Level Export Status, The American Economic Review, Vol.102 (6), pp. 2437-2471.

[33] De Loecker, J. (2013). Detecting Learning by Exporting, The American Economic Review, Vol.5 (3), pp. 1-21.

[34] Dan, L. (2010). Exceptional Exporter Performance? Evidence from Chinese Manufacturing Firms, Job Market Paper, University of Chicago.

[35] Alcal. F. and Ciccone, A. (2004). Trade and Productivity, The Quarterly Journal of Economics, Vol.119 (2), pp. 613-646.

[36] Kasahara, H. and Lapham, B. (2013). Productivity and the decision to import and export: Theory and evidence, Journal of International Economics, Vol.89 (2), pp. 297-316.

[37] Henriques, I. and Sadorsky, P. (1996). Export-Led Growth or Growth-Driven Exports? The Canadian Case, The Canadian Journal of Economics, Vol.29 (3), pp. 540-555. 
[38] Crozet, M., Head, K,. and Mayer, T. (2011). Quality Sorting and Trade: Firmlevel Evidence for French Wine, Review of Economic Studies, Vol.79, pp. 609644 .

[39] Hallward-Driemeier, M., Iarossi, G.,Kenneth and Sokoloff, L. (2002). Exports and Manufacturing Productivity in East Asia: A Comparative Analysis with Firm-Level Data, NBER WP 8894.

[40] Frster, M. and Pearson, M. (2002). Income Distribution and Poverty in the OECD Area: Trends and Driving Forces, OECD Economic Studies, No. 34.

[41] Greenaway, D., Hine, R., and Milner, C. (1995). Vertical and Horizontal IntraIndustry Trade: A Cross Industry Analysis for the United Kingdom, The Economic Journal, Vol.105 (433), pp. 1505-1518.

[42] Rutkowski, A. (2006). Inward FDI, skilled labour, and product differentiation in the CEEC, Journal for East European Management Studies, Vol.11 (2), pp. 91-112.

[43] Robert H. Ballance, Forstner, H., and W. Charles Sawyer. (1992). An Empirical Examination of the Role of Vertical Product Differentiation in North-South Trade, Weltwirtschaftliches Archiv, Bd. 128, H. 2, pp. 330-338.

[44] Choi, C.J., and Shin, H.S. (1992). A Comment on a Model of Vertical Product Differentiation, The Journal of Industrial Economics, Vol.40 (2), pp. 229-231.

[45] Motta, M. (1993). Endogenous Quality Choice: Price vs. Quantity Competition, The Journal of Industrial Economics, Vol.4 (2), pp. 113-131.

[46] Shaked, A and Sutton, J. (1982). Relaxing Price Competition Through Product Differentiation, The Review of Economic Studies, Vol.49 (1), pp. 3-13.

[47] J. Jackold Gabszewicz and J.-F. These. (1979). Price Competition, Quality and Income Disparities, Journal of Economic Theory, Vol.20, pp. 340-359.

[48] Bellu, L.G., and Liberati, P. (2006). Policy Impacts on Inequality: Decomposition of Income Inequality by Subgroups, Food and Agriculture Organization of the United Nations, FAO.

[49] Head, K., and Ries, J. (2004). Exporting and FDI as Alternative Strategies, Oxford Review of Economic Policy, Vol.20 (3). 
[50] Bruce A. Blonigen. (2001). In search of substitution between foreign production and exports, Journal of International Economics, Vol.53 (1), pp. 81-104.

[51] Bruce A. Blonigen. (2005). A Review of the Empirical Literature on FDI Determinants, Atlantic Economic Journal, Vol.33, pp. 383-403.

[52] Yeaple, S.R. (2013). The Multinational Firm, Annual Review of Economics, Vol.5, pp. 193-217.

[53] Yeaple, S.R. (2009). Firm heterogeneity and the structure of U.S. multinational activity, Journal of International Economics, Vol.78, pp. 206-215.

[54] Wolfgang Keller. (2010). International Trade, Foreign Direct Investment, and Technology Spillovers, Handbook of the Economics of Innovation, Vol.2, pp. 793-829.

[55] Todo, Y. (2011). Quantitative Evaluation of the Determinants of Export and FDI: Firm-level Evidence from Japan, The World Economy, Vol.34 (3), pp. $355-381$.

[56] S. Lael Brainard. (1997). An Empirical Assessment of the ProximityConcentration Trade-off Between Multinational Sales and Trade, The American Economic Review, Vol.87 (4), pp. 520-544.

[57] Maggie Chen, X.Y., Michael O. Moore. (2009). Location Decision of Heterogeneous Multinational Firms, Journal of International Economics, Vol.80 (2), pp. 188-199.

[58] John H. Dunning. (2001). The Eclectic (OLI) Paradigm of International Production: Past, Present and Future, International Journal of the Economics of Business, Vol.8 (2), pp. 173-190.

[59] Helpman, E., Marc J. Melitz, and Stephen R. Yeaple. (2004). Export Versus FDI with Heterogeneous Firms, The American Economic Review, Vol.94 (1), pp. 300-316.

[60] Marc J. Melitz. (2003). The Impact of Trade on Intra-Industry Reallocations and Aggregate Industry Productivity, Econometrica, Vol.71 (6), pp. 1695-1725.

[61] Keller, W., and Stephen R. Yeaple. (2013). The Gravity of Knowledge, American Economic Review, Vol.103 (4), pp. 1414-1444. 
[62] Garetto, S. (2013). Input Sourcing and Multinational Production, The American Economic Review, Vol.5 (2), pp. 118-151.

[63] Robert C. Feenstra and Gordon H. Hanson. (2005). Input Sourcing and Multinational Production, The Quarterly Journal of Economics, Vol.120 (2), pp. 729-761.

[64] Deaton, A. and Muellbauer, J. (1980). An Almost Ideal Demand System, The American Economic Review, Vol.70 (3), pp. 312-326.

[65] Avinash K. Dixit and Joseph E. Stiglitz. (1980). Monopolistic Competition and Optimum Product Diversity, The American Economic Review, Vol.67 (3), pp. 297-308.

[66] Rothschild, M. and Stiglitz, J.E. (1971). Increasing risk II: its economic consequences, Journal of Economic Theory, Vol.3, pp. 66-84.

[67] Benassi, C., Chirco, A., and Scrimitore, M. (2002). Income concentration and market demand, Oxford Economic Papers, Vol.54, pp. 584-596.

[68] Benassi C., Chirco, A. and Colombo, C. (2002). The Price Index Effect and Macroeconomic Inefficiency, Rcherches Economiques de Louvain, Vol.68, pp. 385-394.

[69] Atkinson, A.B. (1998). The distribution of income in industrialized countries, Income Inequality, Issues and Policy Options: A symposium, Federal Bank of Kansas City, Jackson Hole, WY.

[70] Atkinson, A.B. (1970). On the measurement of inequality, Journal of Economic Theory, Vol.2, pp. 244-263.

[71] Esteban, J. (1986). Income share elasticity and the size distribution of income, International Economic Review, Vol.27, pp. 439-444.

[72] Formby, J.P., Simity, W.J., and Zheng, B. (1999). The coefficient of variation, stochastic dominance and inequality: a new interpretation, Economics Letters, Vol.62, pp. 319-323.

[73] Lambert, P.J. (2001). The distribution and redistribution of income, Manchester, Manchester University Press, 3rd ed. 
[74] Lambert, P.J., and Pfahler, W. (1997). Market demand and income distribution: a theoretical exploration, Bulletin of Economic Research, Vol.49, pp. $137-151$.

[75] Majumder, A. and Chakravarty, S.R. (1990). Distribution of personal income: development of a new model and its application to US income data, Journal of Applied Econometrics, Vol.5, pp. 189-196.

[76] Aghion P., Caroli, E. and Penalosa, C.G. (1999). Inequality and Economic Growth: The Perspective of the New Growth Theories, Journal of Economic Literature, Vol.37, pp. 1615-1660.

[77] Echevarria, C. (2000). Non-Homothetic Preferences and Growth, Journal of International Trade and Economic Development, Vol.9, pp. 151-171.

[78] Linnemann, L. (2001). The Price Index Effect, Entry, and Endogenous Markups in a Macroeconomic Model of Monopolistic Competition, Journal of Macroeconomics, Vol.23, pp. 441-458.

[79] Persson, T. and Tabellini, G. (1994). Is Inequality Harmful for Growth, The American Economic Review, Vol.84, pp. 600-620.

[80] Yang X. and Heijdra, B.J. (1993). Monopolistic Competition and Optimum Product Diversity: Comment, The American Economic Review, Vol.83, pp. 295-301.

[81] David M. Frankel. (2001). The Retail Price of Inequality, Journal of Urban Economics, Vol.49, pp. 219-239.

[82] Crespo, N. and Maria P. Fontoura. (2007). Determinant Factors of FDI Spillovers What Do We Really Know, World Development, Vol.35 (3), pp. 410-425.

[83] Hugo A. Hopenhayn. (1992). Entry, Exit, and firm Dynamics in Long Run Equilibrium, Econometrica, Vol.60 (5), pp. 1127-1150.

[84] Krugman, P. (1980). Scale Economies, Product Differentiation, and the Pattern of Trade, The American Economic Review, Vol.70 (5), pp. 950-959.

[85] Oliver E. Williamson. (1981). The Economics of Organization: The Transaction Cost Approach, American Journal of Sociology, Vol.87 (3), pp. 548-577. 
[86] Helpman, E. and Razin, A. (1983). Increasing Returns, Monopolistic Competition and Factor Movements, Journal of International Economics, Vol.14, pp. 263-276.

[87] Helpman, E. (1983). A Simple Theory of International Trade with Multinational Corporations, Journal of Political Economy, Vol.92 (3), pp. 451-471.

[88] Helpman, E. (1981). International Trade in the Presence of Product Differentiation, Economies of Scale and Monopolistic Competition - A ChamberlinHeckscher-Ohlin approach, Journal of International Economics, Vol.11, pp. 505-540.

[89] James R. Markusen. (1984). Multinationals, Multi-plant Economies, and The Gains From Trade, Journal of International Economics, Vol.16, pp. 205-226.

[90] Hirsch, S. (1976). An International Trade and Investment Theory of the Firm, Oxford Economic Papers, New Series, Vol.28 (2), pp. 258-270.

[91] Andreoni, J. and Sprenger, C. (2012). Estimating Time Preferences from Convex Budgets, The American Economic Review, Vol.102 (7), pp. 3333-3356.

[92] Frederick, S., Loewenstein, G. and O'Donoghue, T. (2002). Time Discounting and Time Preference: A Critical Review, Journal of Economic Literature, Vol.XL, pp. 351-401.

[93] Laibson, D., Repetto, A. and Tobacman, J. (2007). Estimating Discount Functions with Consumption Choices over the Lifecycle, NBER WP 13314.

[94] Ahmed, W. and Haider, A. and Iqbal, J. (2012). Estimation of discount factor (beta) and coefficient of relative risk aversion (gamma) in selected countries, MPRA 39736.

[95] Contessi, S. (2015). Multinational firms? entry and productivity: Some aggregate implications of firm-level heterogeneity, Journal of Economic Dynamics and Control, Vol.61, pp. 61-80.

[96] Florin O. Bilbiie, Fabio Ghironi, and Marc J. Melitz. (2012). Endogenous Entry, Product Variety, and Business Cycles, Journal of Political Economy, Vol.120 (2), pp. 304-345. 
[97] Ghironi, F. and Marc J. Melitz. (2007). Trade Flow Dynamics with Heterogeneous Firms, The American Economic Review, Vol.97 (2), pp. 356-361. 
VITA

\section{FEIFEI WANG}

2016

2009

2006

2011-present

$2014-2015$

2008-2009

2008
Ph.D candidate, Economics

Florida International University

Miami, Florida

M.A., Economics

University of San Francisco

San Francisco, California

B.A., Economics

Shantou University

Shantou, Guangdong

China

Teaching assistant

Department of Economics

Florida International University

Miami, Florida

Instructor

Department of Economics

Florida International University

Miami, Florida

Fitness Coordinator

Koret Recreation Center

University of San Francisco

San Francisco, California

Jr. Budget Analyst

Office of Planning, Budget and Review

University of San Francisco

San Francisco, California

Skills: R, STATA, Mathematica, MatLab, Tableau, LaTex.

Languages: English and Chinese (Mandarin and Cantonese).

CONFERENCES \& PRESENTATIONS

2014 Participant. Midwest Macro Meeting, Florida International University. 
2013 Participant. International Trade Workshop, Florida International University.

Wang, F.F., (2013). Productivity Exports and Performance - Evidence from Chinese Plants. International Trade Seminar, Florida International University.

Wang, F.F., (2014). Do Firms Learn in Export Market - Evidence from Chinese Manufacturing Firms. International Trade Seminar, Florida International University. 